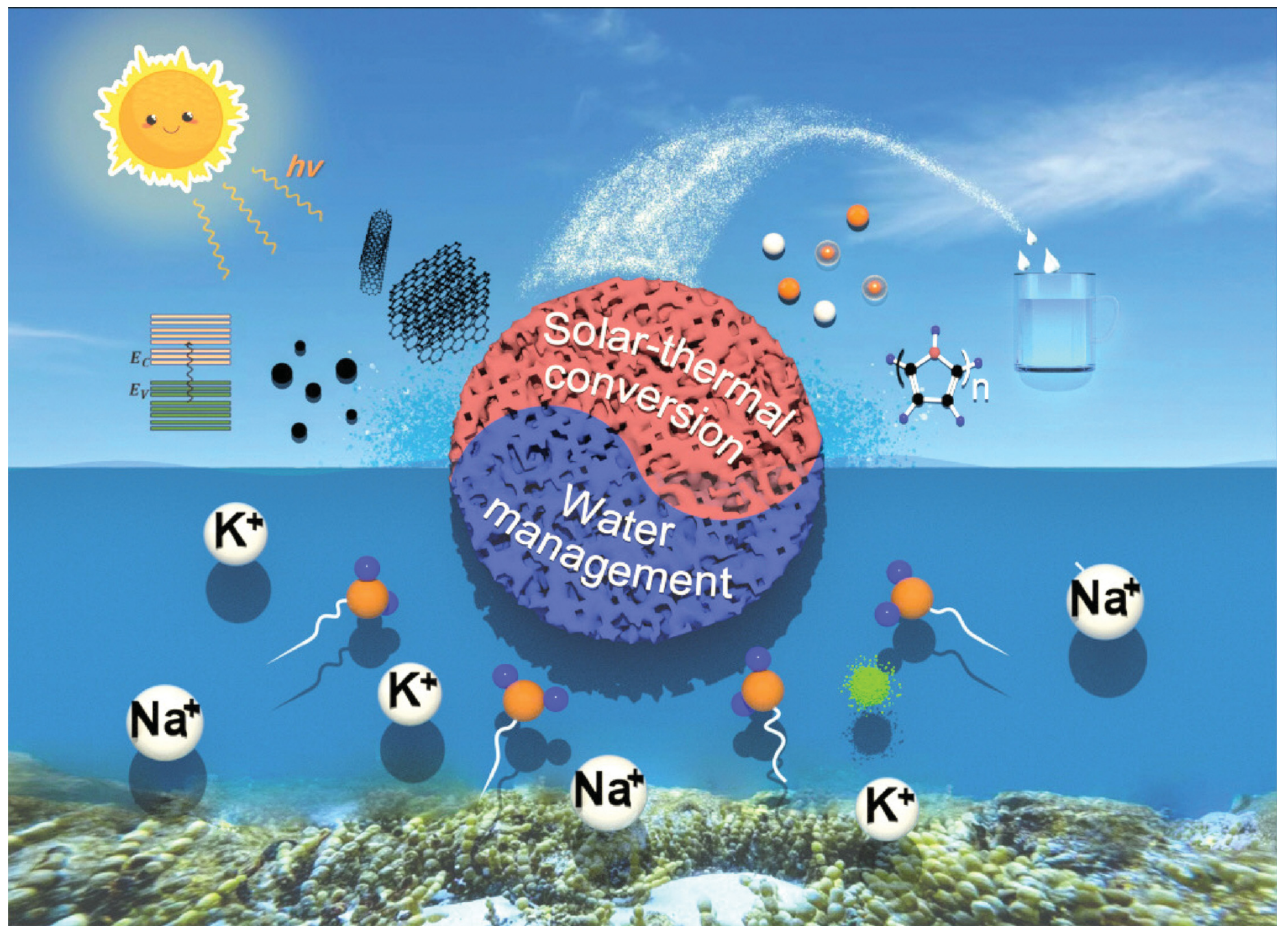

Showcasing research from Dr Qiang Fu's laboratory, School of Civil and Environmental Engineering,

The University of Technology Sydney, NSW, Australia.

Recent developments of hydrogel based solar water purification technology

In this contribution, we review recent progress in hydrogel-based solar water purification systems from two perspectives: improving solar-thermal conversion efficiency and facilitating water transport. The main strategies to achieve higher conversion efficiency include choosing photothermal materials and reducing light reflection and heat loss. Adjusting wettability, tuning the physio-chemical properties of internal channels, and lowering the water vaporization enthalpy are the three main approaches of rapid water transport. This review also provides new insights on remaining challenges and barriers, and future directions in this field.

As featured in:

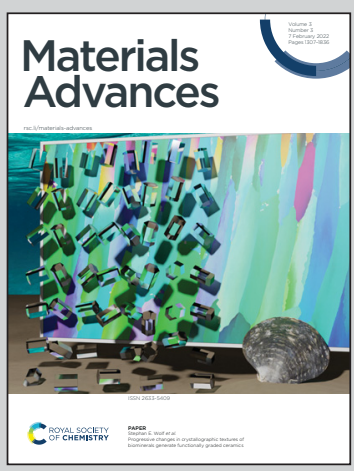

See Qiang Fu et al.,

Mater. Adv., 2022, 3, 1322. 
Check for updates

Cite this: Mater. Adv., 2022, 3,1322

Received 28th September 2021 Accepted 26th December 2021

DOI: 10.1039/d1ma00894c

rsc.li/materials-advances

\title{
Recent developments of hydrogel based solar water purification technology
}

\author{
Shudi Mao, (D) Md Abu Hasan Johir, (D) Casey Onggowarsito, (D) An Feng, (D) \\ Long D. Nghiem (D) and Qiang Fu (D) *
}

\begin{abstract}
Water scarcity is a severe problem all over the world; however, most current large-scale water purification technologies are energy-intensive and require high capital and maintenance costs. Recently, hydrogel-based solar water purification technologies have attracted increasing attention due to their advantages, including easy preparation, less energy intensive, and highly efficient solar absorption and utilization. This review summarizes recent advances in the development of novel hydrogel materials from two perspectives: improving solar-thermal conversion efficiency, and facilitating water transport. The main strategies to achieve higher conversion efficiency include choosing good solar absorbers, constructing a surface to reduce light reflection and reducing heat loss. Adjusting wettability, tuning the physio-chemical properties of internal channels, and increasing the intermediate water content to lower the water vaporization enthalpy are the three main approaches for rapid water transport. This review also provides new insights into future directions and remaining challenges in this field.
\end{abstract}

\section{Introduction}

As an essential substance of life, water is one of the most essential resources for ecological well-being and economic development. Rapid population growth, economic progress, industrialisation of agriculture, dietary changes, and climate

Centre for Technology in Water and Wastewater, School of Civil and Environmental Engineering, University of Technology Sydney, NSW 2007, Australia.

E-mail: qiang.fu@uts.edu.au

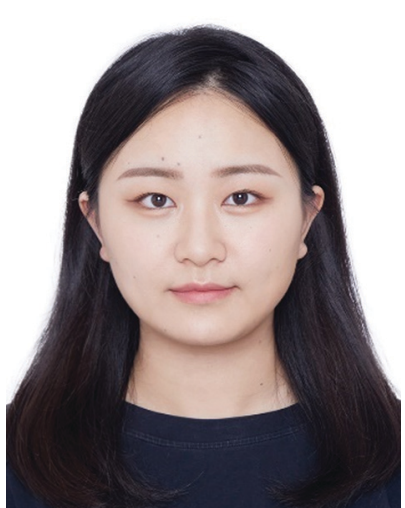

Shudi Mao
Shudi Mao received her BE from Huazhong University of Science and Technology in 2017 and her MS from East China Normal University in 2020. She is currently pursuing her PhD at the University of Technology Sydney, with research interests in advanced polymeric materials design and synthesis for water treatment.

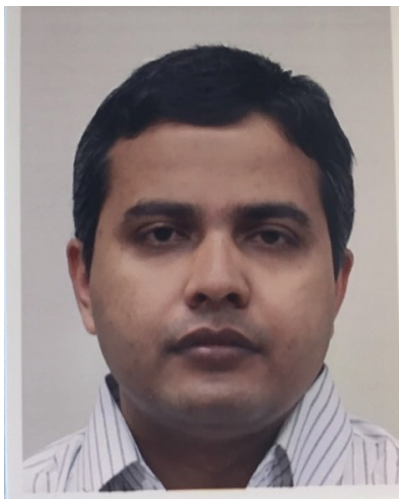

Md Abu Hasan Johir
Dr Md Abu Hasan Johir is currently a Lecturer at the School of Civil \& Environmental Engineering, Faculty of Engineering and Information Technology, and a core membrane at the Centre for Technology in Water and Wastewater (CTWW) at the University of Technology Sydney, Australia. Dr Johir has expertise and research experience in desalination, stormwater and wastewater management, biological wastewater treatment, and resource and energy recovery from seawater and wastewater. Dr Johir also has experience in the synthesis of new materials and membranes for water and wastewater treatment. 
as seawater, brackish water and wastewater that are independent of the hydrological cycle.

Freshwater can be extracted from the ocean or brackish water sources by thermal distillation or filtration technologies. ${ }^{5-9}$ Thermal distillation processes such as multi-stage flash distillation, ${ }^{10}$ multiple effect distillation, ${ }^{11}$ and membrane distillation have been widely used for seawater desalination applications, especially in the Middle East. These technologies require significant thermal energy input, thus, many of them are co-located with and utilize waste heat from thermal power plants to lower energy consumption. Even when co-located with thermal power plants, the energy consumption of these conventional thermal distillation technologies is still quite high, in the range of $5-60 \mathrm{~kW} \mathrm{~h} \mathrm{~m}{ }^{-3}$ of produced freshwater. ${ }^{7,12}$ Filtration-based water purification technologies, such as reverse osmosis (RO) ${ }^{13}$ and electrodialysis, ${ }^{14}$ rely mainly on the separation of salts from water via a semipermeable membrane. RO has been commercialized on a large scale and can achieve a relatively low energy consumption of $c a$. 3-4 $\mathrm{kW} \mathrm{h} \mathrm{m}^{-3}$ of produced freshwater from seawater. ${ }^{15-17}$ However, the RO membrane is susceptible to fouling during operation, and hence frequent chemical cleaning is required. ${ }^{18}$ In the electrodialysis process, cation and anion exchange membranes are used to selectively separate salts from the saline feedwater solution. Electrodialysis is only suitable for brackish water that has about one-fifth of the salinity of seawater ${ }^{19}$ and the energy consumption is also considerable. $^{20}$ Hence, most of the current full-scale water purification technologies consume a significant amount of energy and are therefore costly, encouraging the researchers to develop next-generation cost-effective water purification technologies. These cost-effective water purification technologies will reduce energy consumption or will use renewable energy.

As the most abundant and renewable energy source, solar energy can be used for freshwater production. ${ }^{21}$ A solar still is a simple solar water purification technology. ${ }^{22}$ Fig. 1a illustrates a conventional solar still system, consisting of a sloping glass cover, a black basin with seawater or wastewater, and a

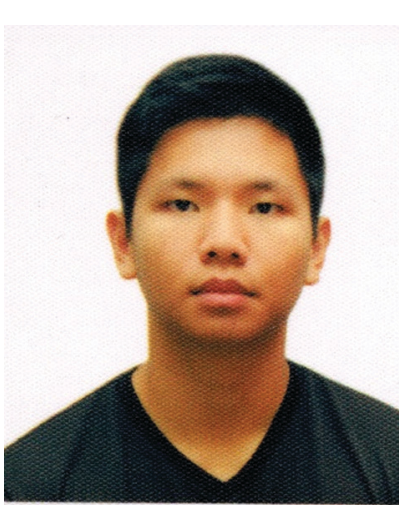

Casey Onggowarsito
Casey Onggowarsito received his $B S$ degree at the University of New South Wales. He is currently working towards his PhD degree at the University of Technology Sydney under the supervision of Dr Qiang Fu. His current research focuses on synthesizing hydrogel-based materials for water purification.

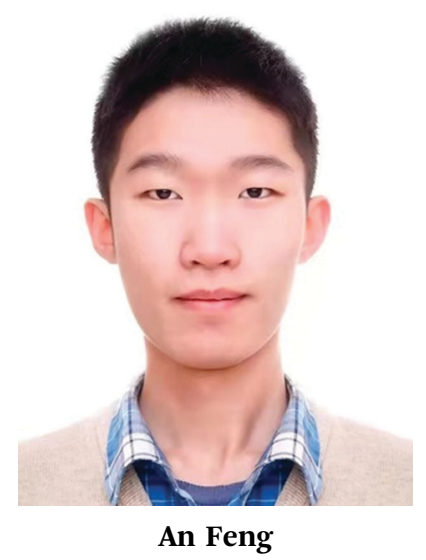

An Feng is a current PhD student focusing on next generation polymeric atmospheric water harvesting materials at the University of Technology Sydney. An completed his BE (Chemical Engineering and Technology) from Chongqing University at 2017, and MEng (Chemical) at the University of Melbourne at 2020.

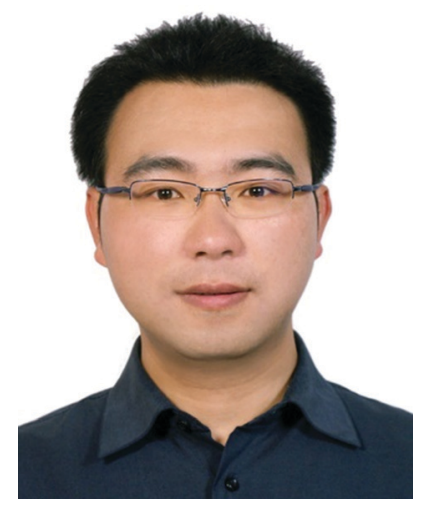

Qiang Fu

Dr Qiang Fu received his BE from Shanghai Jiao Tong University in 2004. He completed his PhD at Fudan University in 2009 before working as a Postdoctoral Fellow at the University of Melbourne. He was an ARC Super Science Fellow (2011-2014) and is currently an ARC Future Fellow (2018-2022). He joined the University of Technology Sydney in 2019. His research interest includes the fields of metalorganic frameworks, membrane (2019). Prof Nghiem's current research work centres around the Water-Energy-Food nexus with a focus on separation technologies, biological waste and wastewater treatment, water reuse, biosolids and organic waste management, and energy and resource recovery from waste and wastewater. 


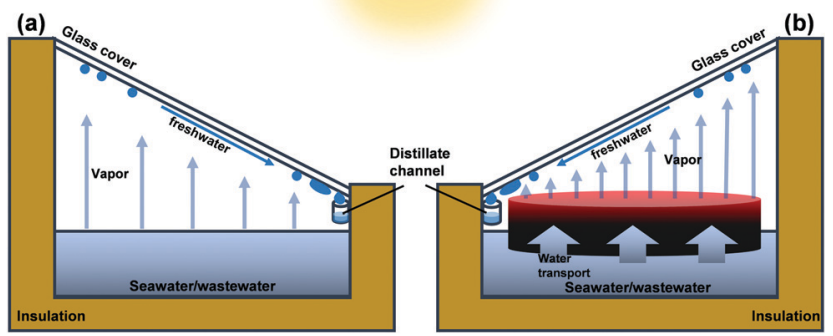

Fig. 1 Schematic illustrations of a single slope (a) solar still and (b) hydrogel based material platform for solar water purification.

thermally insulated enclosure. Because the black basin absorbs solar energy, water evaporates and then condenses on the inner surface of the shelter. As a result, freshwater can be obtained at the lower end of the cover. Unfortunately, the solar vapor generation (SVG) efficiency of such a solar still system is too low (ca. 1-5 $\left.\mathrm{L} \mathrm{m}^{-2} \mathrm{~d}^{-1}\right)^{23}$ to be widely utilized due to insufficient solar absorption and significant thermal loss. To overcome this challenge, novel hydrogel materials have been introduced and incorporated into traditional solar still systems (Fig. 1b). The thin red layer in Fig. $1 \mathrm{~b}$ is above the water surface. It can localize heat in the evaporation interface, reduce heat loss to bulk water, and improve the solar-thermal conversion efficiency, vapor generation rate, and freshwater productivity. ${ }^{24-28}$ These materials are commonly composed of solar absorbers, which can convert solar energy into thermal energy, and porous, low-conductivity, hydrophilic materials that can reduce heat loss and transport water to the evaporation interface. Accordingly, considerable effort has been focused on improving the solarthermal conversion efficiency, enhancing heat insulation, and speeding up water transport. In 2018, Zhao et al. ${ }^{25}$ introduced a hydrogel-based material to reduce the energy demand for evaporation and improve the solar vapor generation efficiency. Specific water states in polymer hydrogels caused by the distinct preference for water molecules of the hydrophilic polymer chains can make the water more active, thereby facilitating the evaporation process. ${ }^{29,30}$ Since then, as a landmark study, it has heightened the interest in this field, and more and more publications on hydrogel-based solar water purification have appeared recently.

Although the development of hydrogel-materials for solar water purification is still in its early stages, many research papers have been published in this field. A timely, thorough review of the recent achievements will highlight key research findings and reveal significant research trends in this field. This review summarises the design principles of hydrogel based materials for solar water purification from two primary directions: improving the solar-thermal conversion efficiency and facilitating water transport with examples from the recent three years' representative research. We also put forward prospects on the future directions and remaining challenges in this field.

\section{Solar-thermal conversion enhancement}

Solar-thermal conversion is the core step of solar water purification, consisting of light-harvesting, photothermal conversion and heat insulation. The light-harvesting competence of the material platform, especially the solar absorbers, is the precondition for attaining sufficient photothermal conversion. Solar radiation might undergo reflection, transmission and absorption when it strikes the surface of solar absorbers, but only the absorbed irradiation is the net energy input for subsequent conversion. Thus, solar absorbers with high irradiation absorptivity and topographical and geometrical designs that reduce reflection and transmission are vital for achieving high conversion efficiency. ${ }^{31}$ The absorbed sunlight energy can be converted into thermal energy by the solar absorbers instead of being re-emitted. A large number of nanomaterials have been employed as solar absorbers, and various photothermal conversion mechanisms are presented based on the different interactions between electromagnetic radiation and the specific categories of solar absorbers. ${ }^{32,33}$ Finally, the generated heat will be confined in the evaporation interface layer through the heat insulation designs ${ }^{27,34,35}$ to reduce heat loss to bulk water and thereby improve the efficiency of heat utilization.

Since a diverse array of factors noted above collaboratively contribute to the solar-thermal conversion competence of the entire solar water purification system, the metric energy conversion efficiency $(\eta)$ has been proposed to quantitatively assess its solar-thermal conversion performance, which can be calculated according to eqn (1): ${ }^{36}$

$$
\eta=\frac{\dot{m} \times h_{\mathrm{v}}}{C_{\mathrm{opt}} \times P_{0}}
$$

where $\dot{m}, h_{\mathrm{v}}, C_{\mathrm{opt}}$ and $P_{0}$ refer to the steady-state evaporation mass flux, the equivalent vaporization latent enthalpy of the water in the hydrogel, the optical concentration on the absorber surface, and the solar irradiation power (normally 1 sun or $1 \mathrm{~kW} \mathrm{~m}^{-2}$ ), respectively.

In order to enhance the energy conversion efficiency, considerable efforts have been devoted to choosing appropriate solar absorbers, modifying surface topography to reduce light reflection, and mitigating heat loss accordingly.

\subsection{Solar absorbers}

Choosing an appropriate solar absorber with full-spectrum strong solar absorption and high solar-thermal conversion capacity is one of the vital design principles. Plentiful nanomaterials have been adapted as solar absorbers in solar water purification, including inorganic semiconductors, plasmonic nanoparticles, carbon-based materials, and conjugated polymers. Different solar absorbers exhibit diverse solar-thermal conversion mechanisms and thus have different selection principles.

2.1.1 Inorganic semiconductors. Semiconductors have been extensively used as solar absorbers due to their highly tunable energy band and inherent thermalization effect. ${ }^{37-39}$ 
Under light illumination, when the exciting energy is higher than the band-gap of the semiconductors, electron-hole pairs are generated. Then, electrons and holes relax to the conduction and valence band edges, and the energy is released in the form of phonons or photons. ${ }^{40}$ The non-radiative relaxed phonons can incur lattice localized heating to finally realize the transformation from light to heat. ${ }^{32,33}$ In the entire photothermal conversion process, the band-gap width is a critical determinant of the amount of energy and heat that can be released. In the solar spectrum, the majority of the radiant energy lies in the infrared $(\sim 52 \%)$, visible $(\sim 45 \%)$ and ultraviolet $(\sim 3 \%)$ wavelength regions, ranging from 300 to $2500 \mathrm{~nm} .{ }^{41}$ Since the infrared band occupies the largest proportion, the narrow band-gap semiconductor nanomaterials that can absorb more infrared energy are more suitable as solar absorbers. ${ }^{39}$

For instance, as a widely used light-harvesting semiconductor, $\mathrm{TiO}_{2}$ has been used as a solar absorber for preparing hydrogel materials. ${ }^{42-45}$ However, under 1 sun, these hydrogels showed a low evaporation rate of $<1.5 \mathrm{~kg} \mathrm{~m}^{-2} \mathrm{~h}^{-1}$ and a low energy conversion efficiency of $<80 \%$. This can be attributed to the wide intrinsic band-gap of $\mathrm{TiO}_{2}$ of $c a .3 \mathrm{eV}$, which corresponds to the absorption of UV-light (wavelength $<400 \mathrm{~nm}$ ). ${ }^{39,46,47}$ In contrast, $\mathrm{Ti}_{2} \mathrm{O}_{3}$ with an extremely narrow band-gap of $\sim 0.09 \mathrm{eV}$ exhibits excellent energy conversion performance. Guo et al. ${ }^{24}$ incorporated $\mathrm{Ti}_{2} \mathrm{O}_{3}$ nanoparticles into sponge-like polyvinyl alcohol (PVA) hydrogels with interconnected pores (Fig. 2a). The SEM and the EDS mapping images (Fig. 2b-d) also confirmed that the $\mathrm{Ti}_{2} \mathrm{O}_{3}$ nanoparticles were uniformly distributed in the network. The optimized samples (LASG3, LASG4 and LASG5, Fig. 2e and f) showed a relatively high solar absorption efficiency of $>96 \%$ and a low reflectance over a broadband of the standard solar spectrum. Correspondingly, the resultant $\mathrm{Ti}_{2} \mathrm{O}_{3}$ /PVA hydrogels showed an extremely high evaporation rate of $3.6 \mathrm{~kg} \mathrm{~m}^{-2} \mathrm{~h}^{-1}$ and an excellent energy conversion efficiency of $c a$. 90\%. In all, semiconducting solar absorbers with a narrow band-gap that can absorb more infrared energy will bring excellent solar-thermal conversion competence to the solar water purification system.

As well as $\mathrm{TiO}_{2}, \mathrm{MnO}_{2},{ }^{48,49} \mathrm{Co}_{3} \mathrm{O}_{4},{ }^{50}$ and $\mathrm{CuO}^{49,51,52}$ other transition metal oxides have been employed as solar absorbers.
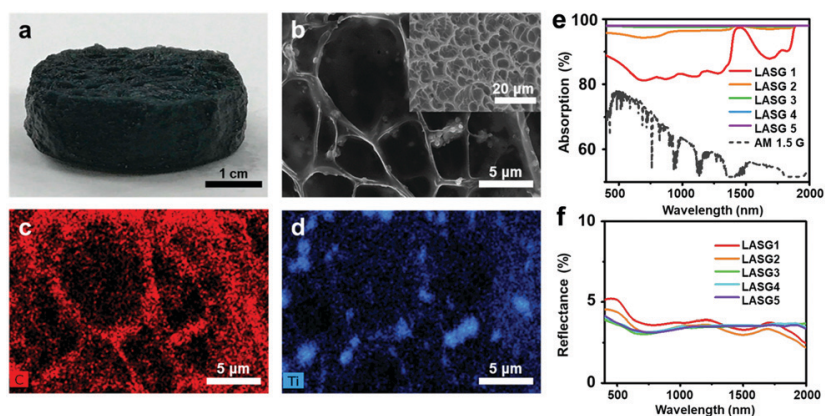

Fig. 2 (a) Photo of the as-prepared $\mathrm{Ti}_{2} \mathrm{O}_{3}-\mathrm{PVA}$ sponge-like hydrogel sample. (b) SEM image of the sponge-like hydrogel and EDS mapping of (c) carbon and (d) titanium. (e) Absorption and (f) reflectance spectra in the wavelength range of 200-2000 $\mathrm{nm}$. Reproduced with permission. ${ }^{24}$ Copyright 2019, American Chemical Society.
Furthermore, transition metal sulfides (such as $\mathrm{MoS}_{2}{ }^{53-56}$ $\mathrm{Mo}_{2} \mathrm{~S}_{3},{ }^{57}$ and $\mathrm{Bi}_{2} \mathrm{~S}_{3}$ ), ${ }^{58}$ nitrides (such as $\mathrm{g}-\mathrm{C}_{3} \mathrm{~N}_{4},{ }^{59} \mathrm{TiN},{ }^{42}$ and $\mathrm{MoN} / \mathrm{Mo}_{2} \mathrm{~N}$ ), ${ }^{60}$ and other novel semiconductors (such as MXene ${ }^{53,61-66}$ and CZTSe) ${ }^{67,68}$ have also shown up in recent research progress, mostly with reasonable evaporation rates between 1.4 and $4 \mathrm{~kg} \mathrm{~m} \mathrm{~m}^{-2} \mathrm{~h}^{-1}$ and energy conversion efficiencies of $>80 \%$. In addition, liquid metals, such as gallium and indium alloy (EGaIn) with a $\mathrm{Ga}_{2} \mathrm{O}_{3}$ (broad bandgap) layer on the surface to prevent the absorption of sunlight, can also be applied as solar absorbers, introducing a dipole layer to narrow the bandgap. ${ }^{69}$

2.1.2 Plasmonic nanoparticles. Plasmonic nanomaterials are metallic materials with a localized surface plasmon resonance (LSPR) effect, which is the resonant oscillation of free electrons induced by photons when the frequency of photons matches that of the natural metal surface electrons. ${ }^{33,70}$ The LSPR effect causes three consequent phenomena: near-field enhancement, hot electron generation, and photothermal conversion. ${ }^{33,71}$ The photothermal effect aided by plasmon happens when metal nanoparticles are lit at their resonance wavelengths. Hot electrons are generated as the electrons get excited from the occupied states to unoccupied ones. By electronelectron scattering, the hot electrons decay, and the hot electron energy can be redistributed, leading to a rapid increase of nanoparticle surface temperature. ${ }^{33}$ Commonly, the LSPR spectral band can be expanded by a hollow structure, asymmetrical design, particle-size shifts, and dielectric surroundings ${ }^{72}$ to compensate for the inherent shortcoming of the narrow absorption spectra of plasmonic nanoparticles caused by their specific geometrics. $^{39}$

Common plasmonic nanoparticles used as solar absorbers include $\mathrm{Ag},{ }^{73-76} \mathrm{Au},{ }^{77} \mathrm{CuS},{ }^{78-81} \mathrm{Cu},{ }^{44,82}$ and so on. Recently, Wang et al. ${ }^{26}$ reported novel plasmonic $\mathrm{Cu}_{7} \mathrm{~S}_{4}-\mathrm{MoS}_{2}-\mathrm{Au}$ composite nanoparticles (CMA NPs) with broad absorption and high photothermal conversion efficiency, which arises from the coupling effect among $\mathrm{Cu}_{7} \mathrm{~S}_{4}, \mathrm{MoS}_{2}$ and $\mathrm{Au}$, as well as the comprehensive utilization of their advantages (Fig. 3a and b). The EDS mappings (Fig. 3c) show the uniform distribution and composition of $\mathrm{Au}, \mathrm{S}, \mathrm{Mo}$ and $\mathrm{Cu}$ elements. It is found that the visible absorption of Au (LSPR peak at $\sim 520 \mathrm{~nm}$ ) and nearinfrared absorption of $\mathrm{Cu}_{7} \mathrm{~S}_{4}$ (LSPR peak at $\sim 1500 \mathrm{~nm}$ ) were successfully integrated with the LSPR absorption of CMA NPs. Compared with $\mathrm{Cu}_{7} \mathrm{~S}_{4}-\mathrm{Au}, \mathrm{MoS}_{2}$ can further increase the absorption of CMA NPs. What's more, the intense plasmonexciton coupling between $\mathrm{Au}$ and $\mathrm{MoS}_{2}$ was accounted for the redshift in their absorption spectrum. Based on the above findings, it can be concluded that the synergy between these three nanoparticles successfully expands the absorption spectrum and enhances absorption in the infrared region, which matches well with the solar irradiation spectrum (Fig. 3e). When the CMA NPs are embalmed into the polydimethylsiloxane (PDMS) matrix, the entire gel material shows enhanced absorption capacity and low reflection (Fig. 3f), leading to an excellent evaporation rate $\left(3.824 \mathrm{~kg} \mathrm{~m}^{-2} \mathrm{~h}^{-1}\right)$ and energy conversion efficiency (96.6\%).

2.1.3 Carbon-based materials. Carbon-based materials have been used as solar absorbers in various studies in recent 

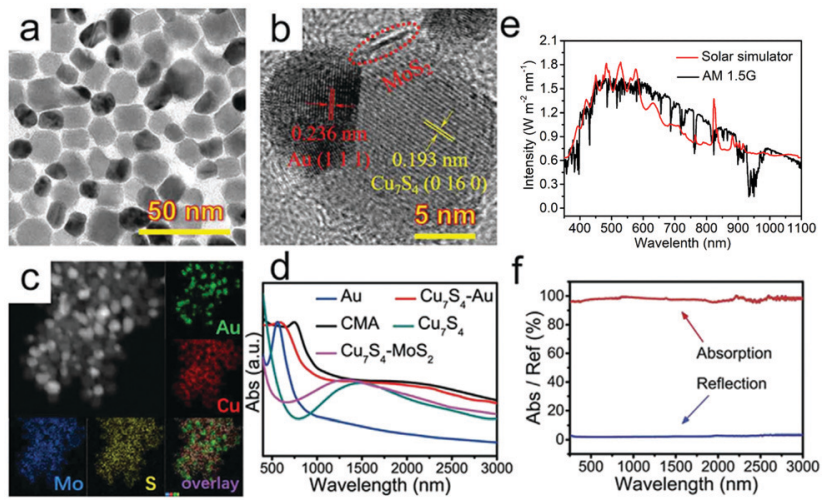

Fig. 3 (a) TEM, (b) HRTEM and (c) HAADF-STEM images as well as corresponding elemental mapping of $\mathrm{Cu}_{7} \mathrm{~S}_{4}-\mathrm{MoS}_{2}-\mathrm{Au}$ nanoparticles. (d) Absorption spectra of different nanoparticles including $\mathrm{Au}_{1} \mathrm{Cu}_{7} \mathrm{~S}_{4}$, $\mathrm{Cu}_{7} \mathrm{~S}_{4}-\mathrm{Au}, \mathrm{Cu}_{7} \mathrm{~S}_{4}-\mathrm{MoS}_{2}$ and CMA NPs. (e) The spectral irradiance density of the solar simulator used in the test and air mass 1.5 global (AM1.5G) tilt solar spectrum. (f) UV-Vis-NIR absorption and reflection spectra of CMA/PDMS hydrogel measured with an integrated sphere. Reproduced with permission. ${ }^{26}$ Copyright 2020, John Wiley and Sons.

years, owing to their excellent light absorption over a broad spectrum, ease of preparation, abundance and low cost. Carbonbased materials include activated carbon, ${ }^{83-86}$ polymer $^{76,87-90}$ or biomass $^{82,91-95}$ derived carbide, carbon black $^{96-101}$ and various amorphous carbon materials and highly graphitized carbon materials, such as graphene, ${ }^{56,59,63,74,77,102-122}$ carbon nanotubes (CNTs) ${ }^{27,123-130}$ and their derivatives.

As for amorphous carbon, the broad light absorption ability comes from the continuous energy levels emanating from the hybrid bonds. ${ }^{131}$ To address the high reflective energy loss and thus improve their light-harvesting efficiency, ${ }^{39}$ considerable efforts have been made in tailoring surface topography, ${ }^{83}$ constructing internal channels, ${ }^{84,86}$ and introducing a second phase. ${ }^{27,34}$ Among these amorphous carbons, activated carbon and carbon black are low cost, readily available materials, and can be easily mass-produced. It is reported that carbon black can be treated with a concentrated $\mathrm{HNO}_{3}$ solution to improve its hydrophilicity and dispersibility in water. ${ }^{96}$ Considering the simple processing method and low cost of $\mathrm{HNO}_{3}$, carbon black can be arguably considered a low-cost material. Combining with a reasonable light path and design, the evaporation rate of these materials can reach $3.86 \mathrm{~kg} \mathrm{~m}^{-2} \mathrm{~h}^{-1}$, and the energy conversion efficiency is as high as $92 \%{ }^{84}$ Using biochar or polymer as the precursor can reduce fabrication $\operatorname{costs}^{91}$ or make the derived carbide more design-oriented. ${ }^{35}$

Different from amorphous carbon, the photothermal conversion effect of crystalline carbon (graphene and highly graphitized carbon materials) arises from the conjugated $\pi$ bonds. The large number of conjugated $\pi$ bonds allows electrons to be excited at almost every wavelength of the solar spectrum, resulting in various $\pi-\pi^{*}$ transitions. The excited electrons relax through electron-phonon coupling, so energy is transferred from the excited electrons to the vibration mode of the entire atomic lattice, which causes the macroscopic temperature of the material to increase. ${ }^{33}$ It is noted that a solar water purification system containing reduced graphene oxide (rGO) generally exhibits a relatively high evaporation rate (2.33$2.72 \mathrm{~kg} \mathrm{~m}^{-2} \mathrm{~h}^{-1}$ ) and higher energy conversion efficiency (>90\%) compared to the systems based on graphene and graphene oxide (GO). ${ }^{59,63,74,77,102-119}$ This result may be attributed to the residual functional groups (i.e. epoxy, hydroxyl) on the surface of rGO, which can be further investigated.

As the youngest carbon nanomaterials, carbon dots (CDs) $)^{132-134}$ have attracted attention due to their broad light absorption spectrum $(200-800 \mathrm{~nm})$ and high photothermal conversion efficiency $(>90 \%)$, so that CDs can meet the requirements of solar absorbers. ${ }^{135}$ To further improve the performance of CDs for solar water purification, future development directions include structure adjustment and surface group modification without lowering crystallinity or wetting properties.

2.1.4 Conjugated polymers. Apart from the aforementioned inorganic materials, unique, organic polymers with conjugated backbone structures (Fig. 4) are often used as solar absorbers in solar water purification. Due to the $\pi$-conjugated backbones of $\mathrm{sp}^{2}$-hybridized carbon, conjugated polymers have splitting energy levels and adjustable band-gaps, resulting in a similar performance to inorganic semiconductors. ${ }^{39,136}$ Similarly, to improve the solar-thermal conversion performance, several strategies have been proposed to reduce the forbidden bandwidth and red-shift the main absorption peak to the NIR region. For conjugated polymers, this is usually accomplished by oxidation doping. ${ }^{136}$ In addition, another advantage of polymer solar absorbers is that they have higher compatibility with hydrogel networks, thereby improving manufacturing processability.

A representative polymer solar absorber is polypyrrole (PPy), which has been reported in recent studies. ${ }^{25,75,130,137-148}$ For instance, Zhao et al. ${ }^{25}$ introduced PPy into a PVA-based hydrogel network and achieved a high evaporation rate of $3.2 \mathrm{~kg} \mathrm{~m} \mathrm{~m}^{-2} \mathrm{~h}^{-1}$ with an excellent energy conversion efficiency of $94 \%$. In the next year, the same group reported a PPy/ chitosan/PVA hydrogel platform that exhibited an enhanced solar vapor generation capacity of $3.6 \mathrm{~kg} \mathrm{~m}{ }^{-2} \mathrm{~h}^{-1} \cdot{ }^{137}$ Recent

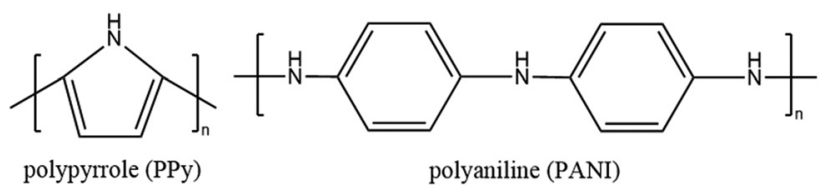

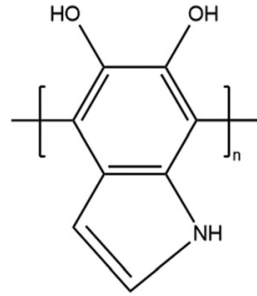

polydopamine (PDA)

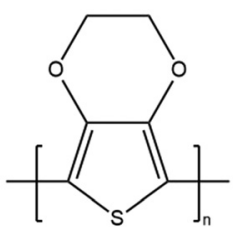

poly(3,4-ethylenedioxythiophene) (PEDOT)
Fig. 4 Chemical structures of PPy, PANI, PDA and PEDOT with $\pi$-conjugated backbones of $\mathrm{sp}^{2}$-hybridized carbon. 
research on conjugated polymer solar absorbers has been extended to polyaniline (PANI), ${ }^{149,150}$ poly(3,4-ethylene dioxythiophene) (PEDOT), ${ }^{151,152}$ polydopamine (PDA), ${ }^{6,153-156}$ perovskite hole layer material DPP-2T, ${ }^{157}$ and covalent organic frameworks (COFs). ${ }^{122,158}$ Furthermore, conjugated copolymer materials such as poly(aniline-co-pyrrole) ${ }^{34}$ have also shown up in recent research, proving a novel approach for solar water purification by combining the advantages of two polymers.

2.1.5 Literature comparison between different solar absorbers. Although many reviews have broadly compared the performance of different solar absorbers, rarely have research articles fairly compared their performance in the same hydrogel matrix. Sun et $a l^{153}$ prepared four hydrogels composed of the same polymer materials but different solar absorbers, such as plasmonic nanoparticle CuS, carbon-based material GO, and conjugated polymers PPy and PDA, and conducted solar water evaporation experiments. The calculated evaporation rates are 1.6, $1.66,1.74$ and $1.84 \mathrm{~kg} \mathrm{~m} \mathrm{~m}^{-2} \mathrm{~h}^{-1}$ for CuS, GO, PPy and PDA, and their energy conversion efficiencies are $79.6 \%, 83 \%$, $87 \%$ and $92 \%$, respectively. In this study, conjugate polymers showed the best performance compared with plasmonic nanoparticles and carbon-based materials, but this inference is limited to the performance of particular materials under specific conditions. In addition, inorganic semiconductors are not involved in this comparison. It is expected that there will be more research on the application of various solar absorbers and performance comparison, which will provide an insightful perspective on the selection of suitable solar absorbers.

\subsection{Surface topography modification}

The most effective strategy to enhance the light-harvesting capacity of the hydrogel platforms is to tailor surface topography to reduce light reflection. ${ }^{69,78,83,149,159,160}$ Some materials ${ }^{78,149}$ are porous, so rough surfaces contribute to higher light-harvesting ability. Recently, researchers have proposed novel design methods to tailor undulating surfaces, including mold embossing, ${ }^{160}$ in situ template-assisted fabrication, ${ }^{83}$ and external magnetic field-assisted methods. ${ }^{159}$

Mold embossing is an ordinary method to produce hydrogels with corresponding patterns, but the cost of processing the mold is high and it is troublesome to make modifications to the mold. As a result, it is more suitable for subsequent confirmed mass production. Guo et al. first reported the in situ templateassisted fabrication method. ${ }^{83}$ They used air, glass and a specific solvent (pentanol) as templates to produce a grooved surface hydrogel (G-SH), a flat surface hydrogel (F-SH) and a sharply dimpled surface hydrogel (D-SH), respectively. The commercially available AC paper was used as the substrate and solar absorber, and a transparent PVA hydrogel layer was then prepared on the substrate to prepare a composite solar steam generator. As seen from the SEM images, G-SH has a rough surface with shallow holes (Fig. 5A and B), but a higher magnification image (Fig. 5C) reveals a relatively smooth sheet structure; F-SH exhibits a reasonably smooth outermost surface that is decorated with very shallow holes (Fig. 5D) and shows a similar sheet-like structure at higher magnification (Fig. 5E and F).

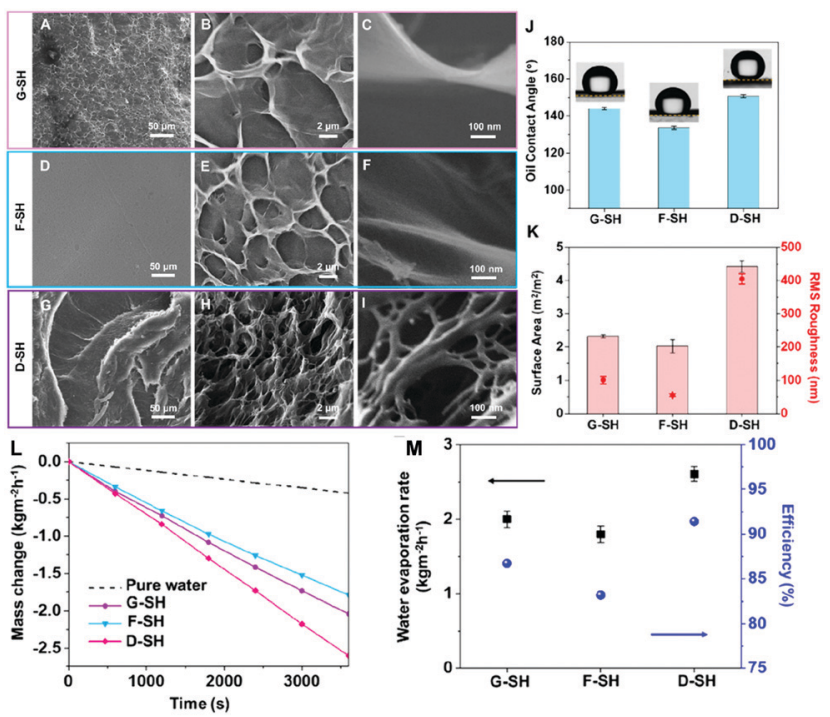

Fig. 5 SEM images of different surface topography: (A-C) G-SH, (D-F) F$\mathrm{SH}$ and $(\mathrm{G}-\mathrm{I}) \mathrm{D}-\mathrm{SH}$. (J) The underwater oil (1,2-dichloroethane) contact angle of each modified surface. (K) The optical profilometer test results revealed the surface area and root-mean-square (RMS) roughness of each sample. (L) The water mass changes, $(M)$ water evaporation rates and energy conversion efficiencies of different samples under 1 sun. Reproduced with permission. ${ }^{83}$ Copyright 2019, American Chemical Society.

For the D-SH sample, distinct "canyons" could be seen, resulting in a strongly dimpled surface topography (Fig. 5G). The porous structures are strewn through the canyon clusters (Fig. $5 \mathrm{H}$ ). Furthermore, D-SH has nanoscale pores nested in its microsized porous structure (Fig. 5I), which neither G-SH nor F-SH has. D-SH has the highest RMS roughness with a surface area about 5 times that of its shadow area (Fig. 5K). As a result, D-SH also shows super-oleophobicity (Fig. 5J, OCA $\geq 150^{\circ}$ ), indicating that the super-wettability of PVA can be further tweaked by increasing the surface roughness. Due to the roughest surface, the most significant evaporation interface and the highest hydrophilicity, D-SH displays the best SVG performance (Fig. 5L and M) with a water evaporation rate of $2.6 \mathrm{~kg} \mathrm{~m}^{-2} \mathrm{~h}^{-1}$ and an energy conversion efficiency of $c a .91 \%$.

The other novel surface modification method is only effective for solar absorber particles with magnetism, such as the $\mathrm{Ni@RF@SiO}{ }_{2}$ core-shell nanoparticles in Yang et al.'s work. ${ }^{159}$ The nickel in the center of the core-shell structure is the source of magnetism (Fig. 6g). The method primarily involves applying an external magnetic field to the magnetic solar absorber in order to adjust its distribution and convexity on the polymer surface, thus altering the surface morphology. In Fig. 6, M-20, M30 and M-40 represent composite membranes with particle concentrations of 20,30 , and $40 \mathrm{wt} \%$, respectively. From the SEM images (Fig. 6a-d and h-k), the number and height of surface microstructures increase in proportion to the strength of the magnetic field and the population of magnetic particles. As a result, M-40 has the roughest surface due to the highest external magnetic field and highest solar absorber concentration, showing the best solar-driven steam generation performance of $2.25 \mathrm{~kg} \mathrm{~m}^{-2} \mathrm{~h}^{-1}$ at 95\% energy conversion efficiency (Fig. 6e and f). 


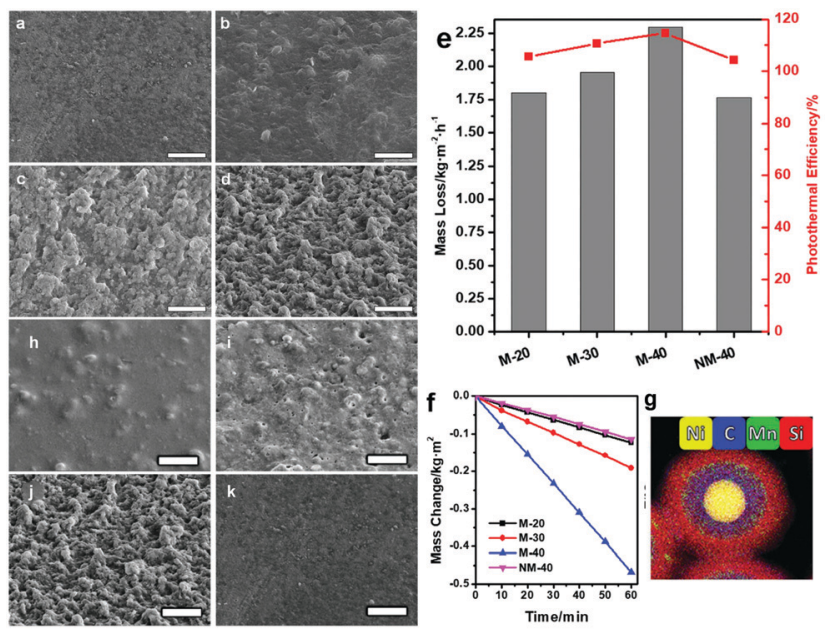

Fig. $6 \mathrm{SEM}$ images of the $\mathrm{Ni}_{40} \mathrm{C}_{20}$ /PVA composite film, with (a) $0 \mathrm{mT}$, (b) $100 \mathrm{mT}$, (c) $200 \mathrm{mT}$ and (d) $400 \mathrm{mT}$ magnetic field applied during the gelation process and the SEM images of (h) $M-20$, (i) $M-30$, (j) $M-40$ and (k) NM-40 (scale bar $=50 \mu \mathrm{m}$ ). (e) The evaporation rates and energy conversion efficiencies of different films. (f) Water mass changes over time without light illumination at $20^{\circ} \mathrm{C}$ on various films. (g) EDX mapping image of Ni@RFaSiO 2 core-shell nanoparticles. Reproduced with permission. ${ }^{159}$ Copyright 2021, John Wiley and Sons.

Increasing the surface roughness of the hydrogel can simultaneously improve the light harvesting competence and the effective evaporation surface area, which is beneficial to increase the production and energy conversion efficiency of the interfacial evaporator device. In contrast, the template-assisted surface construction method is more general, and suitable templates can be used for various polymers for further development, while the method based on an external magnetic field is only ideal for magnetic solar absorbing particles, and has certain limitations.

In addition, 3D printing is a promising technology to construct surface topography. Yuan et al. ${ }^{161}$ firstly reported a 3D hierarchically porous cellulose/alginate/carbon black hydrogel via direct ink writing (DIW) 3D printing. Although the evaporation performance in this work is not impressive, it proves that 3D printing technique can be used to produce hydrogels with certain surface patterns for solar water purification.

\subsection{Reducing heat loss}

Aside from selecting the right solar absorber and tailoring surface topography, minimizing heat loss to the atmosphere and/or the bulk water is another effective way to boost solarthermal conversion efficiency and the overall water purification output. In principle, heat loss occurs in three ways, ${ }^{159}$ including the thermal radiation of the platform, convection between the platform and the ambient air, and heat conduction from the surface to bulk water, which are all directly linked to the temperature of the platform or bulk water. Therefore, the surface or bulk water temperature is a critical reference value for measuring the heat loss of the platform. Current methods to reduce heat loss primarily rely on changing the distribution of solar absorbers, ${ }^{27,35,73,75,83,100,112,141}$ and incorporating heat-insulating materials.
As for the distribution of solar absorbers, uniform distribution of solar absorbers in the hydrogel matrix can reduce the heat flow inside the entire platform, thereby reducing heat loss compared to an unevenly dispersed system. For instance, the carboxylated CNTs can be uniformly distributed in the PAM matrix, improving energy conversion efficiency. ${ }^{27}$ However, the even distribution of solar absorbers cannot mitigate heat dissipation to the surrounding environment. Therefore, researchers have designed multi-layered structures with all solar absorbers in a thin top layer to confine the energy around the evaporation interface. ${ }^{73,75,83,100,112,141}$ On this basis, Guo et al. ${ }^{35}$ have developed a 'top-thin-layer' with magnetic field-driven solar absorbers to further reduce the interface contact heat loss between different layers. In this work, they use a magnet to carry the iron-based metal-organic framework (Fe-MOF) derived solar absorber particles to one side of the PVA/konjac glucomannan (KGM, which also improves the heat insulation capacity) hydrogel to form a layered hybrid hydrogel evaporator (HHE, Fig. 7f). HHE 3 with a KGM/PVA weight ratio of $0.16: 10$ shows the highest evaporation rate $\left(3.2 \mathrm{~kg} \mathrm{~m}^{-2} \mathrm{~h}^{-1}\right)$ at the highest energy conversion efficiency (90\%). As seen from Fig. $7 \mathrm{a}-\mathrm{c}$, the black solar absorbers are located at the top of HHE 3, which is also confirmed by EDS mapping (Fig. 7d and e). The surface temperature and bulk water temperature reach equilibrium temperatures of 31 and $22{ }^{\circ} \mathrm{C}$, as shown in Fig. $7 \mathrm{~g}$. According to the COMSOL simulation results (Fig. 7h), HHE 3 can keep heat close to the evaporation surface to reduce heat loss. This study thus proved its higher energy conversion efficiency compared with the evaporator with evenly distributed solar absorbers. In addition, there are some other methods to confine the solar absorbers on the surface layer, such as using the difference in surface tension between ethanol and water, ${ }^{134}$ concentrating them on one end of the hydrogel under gravity, ${ }^{82}$ carbonizing the upper side of the hydrogel, ${ }^{90,162}$ and so on.

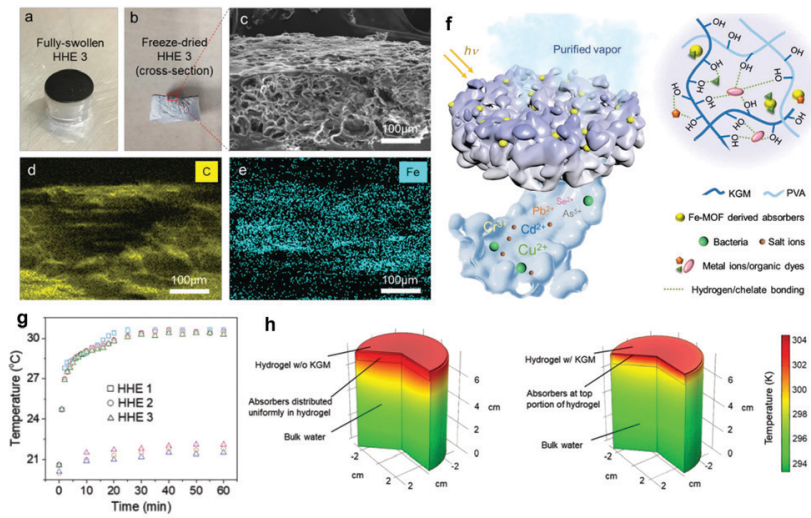

Fig. 7 Spatial distribution of absorbers in HHE 3. Photographs of (a) fully swollen HHE 3; (b) cross-section of freeze-dried HHE 3; (c) SEM image of the top portion of $\mathrm{HHE} 3$; the corresponding EDS mappings of (d) $\mathrm{C}$ and (e) iron elements. (f) Schematic illustration of solar water purification using HHEs. (g) Under 1 sun irradiation, the temperatures at both the hydrogel evaporator surface and in the bulk water. (h) COMSOL simulation results of the temperature distribution of a control sample (pure PVA hydrogel with uniformly distributed absorbers) and $\mathrm{HHE}$ 3. Reproduced with permission. ${ }^{35}$ Copyright 2020, John Wiley and Sons. 
For heat management, in addition to using solar absorbers as the heat-generating phase, the other phase in the platform usually exists as heat insulating substances. Hydrogels with high water content have inherent heat insulation ability. To further enhance the overall heat insulation, most studies add a heat insulation layer, such as $\mathrm{PSS},{ }^{103} \mathrm{PS},{ }^{87,139} \mathrm{PE},{ }^{78,79}$ $\mathrm{EPE},{ }^{92} \mathrm{TE}^{125}$ foam and so on, at the bottom of the evaporation flatform. Yet, recent research incorporated heat confinement components such as specific aerogel spheres ${ }^{34}$ and hydrophobic associations ${ }^{27}$ into the hydrogels to lift their overall heat insulation performance. Tan et $a .^{34}$ controlled the gelation conditions and prepared poly(aniline-co-pyrrole) hollow spheres/PVA hybrid hydrogel with gradient distribution of silica aerogel particles (Fig. 8c). The resultant hydrogel has a hydrophobic rough upper surface and a smooth hydrophilic bottom surface (Fig. 8a and b). The EDS mapping result confirmed the gradient distribution (Fig. 8g-i) and the element's contents analysis in different parts (Fig. 8j). As a result, the upper part of the hydrogel has a lower thermal conduction $\left(0.2 \mathrm{~W} \mathrm{~m}^{-1} \mathrm{~K}\right)$ than the bottom part $\left(0.54 \mathrm{~W} \mathrm{~m}^{-1} \mathrm{~K}\right)$, resulting in higher temperature variations in the top surface than bulk water (Fig. 8k). Zhang et al. ${ }^{27}$ used hydrophobic lauryl methyl acrylate (LMA) micelles as cross-linkers to construct hydrophobic associations in a PAM hydrogel. As shown in Fig. 81, the hydrophobic and hydrophilic phases are coexisting in the hydrogel, resulting in isolated micropores. If the temperature of the hydrogel increases, the interaction between molecular chains and water molecules weakens, resulting in a decrease in the water content of hydrogel. Due to the higher temperature at the

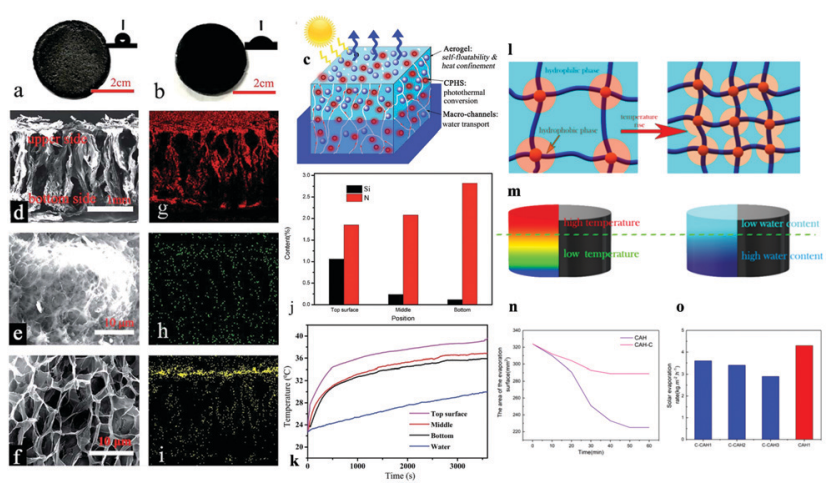

Fig. 8 Photos of the (a) upper and (b) bottom surface of the CPHS/ aerogel functionalized hydrogel; inset is the contact angle image. (c) Solar steam generation schematic based on functional hybrid hydrogels. SEM images of (d) cross-section of the hydrogel, (e) upper and ( $f$ ) bottom surface of the hydrogel; and EDS mapping of (g) C, (h) N and (i) Si. (j) Si and $\mathrm{N}$ contents of different parts from EDS. (k) Under 1 sun, temperature-time plots of various sections of the hydrogel and bulk water. Reproduced with permission. ${ }^{34}$ Copyright 2019, Royal Society of Chemistry. Schematic illustration of $(l)$ the composition of a hydrophobic association hydrogel's microphase separation and the structural change caused by temperature; and $(\mathrm{m})$ the correlation between the temperature distribution and the water content in the hydrophobic association hydrogel. (n) Changes in the CAH's and C-CAH's evaporation surface area. (o) C-CAHs' evaporation rates. Reproduced with permission. ${ }^{27}$ Copyright 2020, American Chemical Society. top of the hydrogel, there is less water around the evaporation interface (Fig. 8m), reducing heat loss from the top surface caused by excess water. A control hydrogel sample was prepared to demonstrate this speciality by omitting the hydrophobic association (C-CAH). This sample showed slower shrinkage and a larger evaporation surface area than $\mathrm{CAH}$ (Fig. 8n). As a result, with less heat loss, the evaporation rate of hydrophobic association hydrogel is higher than that of C-CAHs (Fig. 80). More recently, $\mathrm{Wu}$ et al. ${ }^{163}$ reported a multi-layer spherical evaporator composed of a PS core and multi-layer outer coatings (PS-cellulose-PDA-PPy-PDA). This design reduces its density and restricts water transport only through the outer hydrophilic layers. Only a thin polymer coating can come in contact with the water, thereby limiting heat loss from the evaporation surface to the bulk water. In all, hydrophobic ingredients have been proven to be thermal confinement components to reduce heat loss.

\section{Enhancing water transport/ activation capacity}

Water management, including water transport and water activation, is another critical process that determines the overall performance of solar water purification. Fast water transport speed can ensure continuous water supply to the evaporation interface. Adjusting the wettability and tuning the internal water transport channels are the two main design principles to enhance water transport. In addition, the capacity of the platform to promote water activation is essential to decrease the water vaporization enthalpy to improve the energy conversion efficiency and the evaporation rate (see eqn (1) in Section 2).

\subsection{Adjusting the wettability}

A practical method is to reduce the surface wettability to improve the water transport competence. Examples include using hydrophobic polydimethylsiloxane (PDMS) as the top layer, ${ }^{123}$ adding hydrophobic $\mathrm{Si}$ aerogels mainly in the upper part, ${ }^{34,104,164}$ selectively decorating the upper surface with PFOTS $^{162}$ and reducing hydrophilic GO into hydrophobic rGO at the top side via laser. ${ }^{165}$ Furthermore, Guo et al. ${ }^{36}$ have reported a patchy surface with hydrophobic and hydrophilic parts for higher water transport speed and excellent SVG performance ( $4 \mathrm{~kg} \mathrm{~m}^{-2} \mathrm{~h}^{-1}$ with $93 \%$ energy conversion efficiency Fig. 9). The hydrogel has a partial trichloro(octadecyl)silane (OTS) modified surface, with the island-shaped patches being hydrophobic and the rest being hydrophilic (Fig. 9a). The thickness of the water film increased as a large portion of the water is confined in the hydrophilic region; thus, the effect of hydrogel surface on the outmost water molecules is decreased, resulting in faster evaporation (Fig. 9b). The optical images and increasing water contact angles confirm the successful OTS modification of the surface of the hydrogels (Fig. 9d-k). Moreover, the introduction of hydrophobic components into the hydrogels can lead to the formation of internal gaps, thus ensuring rapid water replenishment. ${ }^{27}$ 


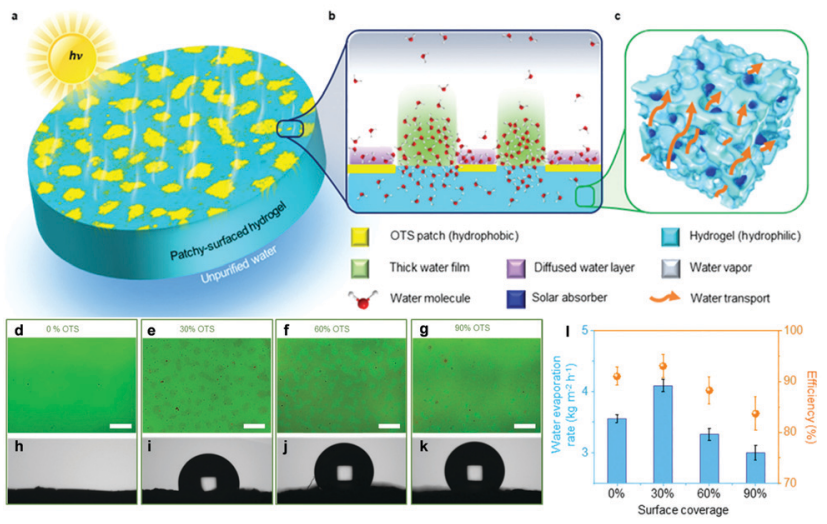

Fig. 9 (a-c) Schematic illustration of patchy-surface hydrogels (PSHs) (d-k) Optical images and contact angles of PSHs with ( $d$ and h) $0 \%$, (e and i) $30 \%$, (f and j) $60 \%$, and (g and k) $90 \%$ OTS covered surfaces. The scale bars are all $20 \mathrm{~mm}$. (l) The evaporation rates and corresponding energy conversion efficiencies of PSH under 1 sun. Reproduced with permission. ${ }^{36}$ Copyright 2020, Royal Society of Chemistry.

\subsection{Tuning internal water channels}

The internal water channel is a vital channel for rapid water transport that can be constructed from three perspectives: size ${ }^{53,86,116}$ direction, ${ }^{48,64,99,124,166}$ and structure ${ }^{167}$ to enhance the pumping force and/or capillary effect.

To tune the size of the water channel, Liang et al. have put forward a simple and fast construction method via fermentation. However, the evaporation rate is not high enough $\left(1.611 \mathrm{~kg} \mathrm{~m}^{-2} \mathrm{~h}^{-1}\right)$ due to the large pores formed $(900-2540 \mu \mathrm{m}){ }^{86}$ Li et $a .^{53}$ used the ice-template method to narrow the size of the inner channel to the submicrometer range, inducing a strong capillary force to achieve rapid water transport over a long distance. The pore structures and size distribution are shown in Fig. 10a-e, and the highest evaporation rate is $6.35 \mathrm{~kg} \mathrm{~m}^{-2} \mathrm{~h}^{-1}$ over a long transport distance of $8 \mathrm{~cm}$ (Fig. 10f). In addition to the uniform size channel, Meng et al. ${ }^{116}$ proposed an $\mathrm{N}$-doped rGO aerogel with ring-like gradient vertically aligned microchannels as shown in Fig. $10 \mathrm{~g}$.

From Fig. 10h-j, it is found that the spacing and wall thickness increase from the center to the edge, and a specific channel size distribution is realized by introducing a concentration gradient of $\mathrm{NH}_{4} \mathrm{OH}$ (as antifreeze) before freeze-drying. The gradient channel size distribution can ensure concentrated pumping in the center, as reflected by the simulation results in Fig. 10k, leading to a high evaporation rate of $2.53 \mathrm{~kg} \mathrm{~m}^{-2} \mathrm{~h}^{-1}$.

Inspired by the water transport in trees in nature, vertically aligned internal channels have the potential to quickly transport water from the bottom of the evaporation generator to the top and release vapor quickly (Fig. 11a). The direction freezing method $^{64,99}$ is usually used to construct vertically aligned channels. For example, Yu et al. ${ }^{64}$ prepared a PVA/MXene hydrogel with wood-like vertically aligned channels using the above method (Fig. 11b). The hydrogel with vertically aligned channels (TIH3) represents a higher water mass change than that of bulk water, MXene membrane (MM) and non-treeinspired hydrogel (n-TIH3) (Fig. 11c). As a result, TIH3 shows

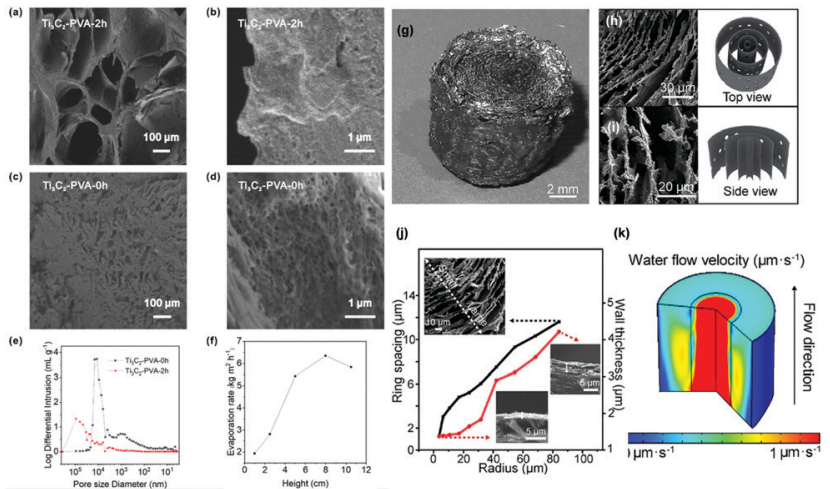

Fig. $10(a-d)$ SEM images of $\mathrm{Ti}_{3} \mathrm{C}_{2}-\mathrm{PVA}-2 \mathrm{~h}$ and $\mathrm{Ti}_{3} \mathrm{C}_{2}-\mathrm{PVA}-0 \mathrm{~h}$. (e) Pore size distribution. (f) The evaporation rates and the corresponding maximum water transport height. Reproduced with permission. ${ }^{53}$ Copyright 2020, American Chemical Society. (g) Photo of the N-RGO aerogel with a ring-like architecture. The SEM images and corresponding schemes from (h) the top and (i) side views. (j) From the middle to the edge, the wall thickness and spacing increase. (k) Simulation of the ring-like aerogel's water flow velocity with gradient microchannels, suggesting concentrated pumping in the middle. Reproduced with permission. ${ }^{116}$ Copyright 2020 , American Chemical Society.

a high evaporation rate of $2.71 \mathrm{~kg} \mathrm{~m}^{-2} \mathrm{~h}^{-1}$ at $90.7 \%$ energy conversion efficiency as a vapor generator in solar water purification. Besides, the tortuosity of the internal channels can be adjusted by introducing chitosan (CTS) content in the hydrogels. ${ }^{48,166}$ With a higher content of CTS, lower-tortuosity channels can be achieved to speed the water transport as well as increase the evaporation rate and energy conversion efficiency (Fig. 11d). Xu et al. have proposed a radial ice-template method (Fig. 11g) to achieve radial vertically-aligned channels, which are more similar to the internal channels of a tree (Fig. 11e). ${ }^{124}$ The aerogel with radial vertically-aligned channels

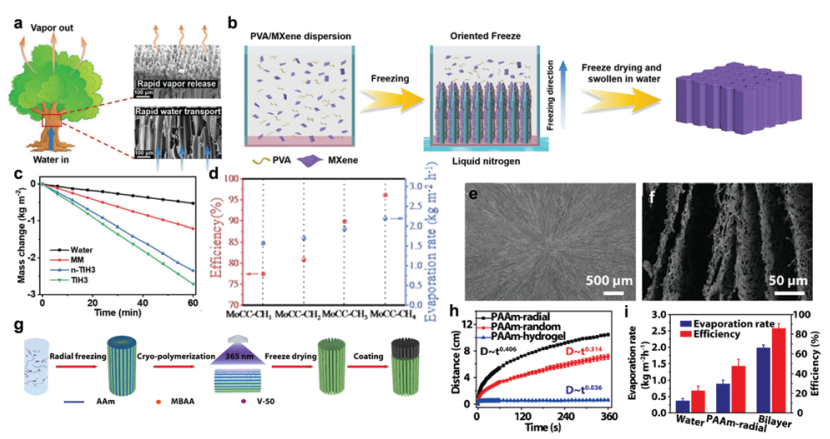

Fig. 11 (a) Schematic illustration of the water transport in tree from root to the top with the SEM images of the top and bottom of wood. (b) Schematic illustration of the direction freezing method. (c) Water mass loss for pure water, MM, n-TIH3, and TIH3 under 1 sun. Reproduced with permission. ${ }^{64}$ Copyright 2020, John Wiley and Sons. (d) Evaporation rates and energy conversion efficiencies of MoCC-CHs. Reproduced with permission. ${ }^{166}$ Copyright 2020, American Chemical Society. (e and f) SEM images of radially aligned channels and micropores. (g) Schematic illustration of the radial freezing method. (h) Water transport distance over time. (i) Water evaporation rate and energy conversion efficiency of PAAm-based aerogels with different channel directions. Reproduced with permission. ${ }^{124}$ Copyright 2019, American Chemical Society. 
(a)

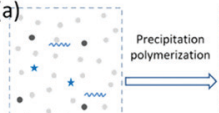

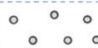
$\because 0$ - :AA O:HFBMA mU:SOS $\star$ :APS (b)
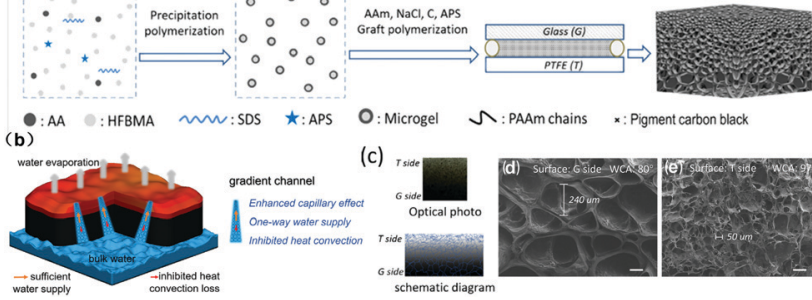

O: Microgel $ح$ : PAAm chains $\quad x$ : Pigment carbon black

(c)
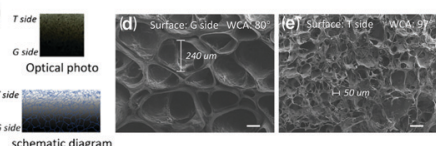

Fig. 12 (a) Fabrication process of a gradient structured hydrogel via the G-T template method. (b) Schematic illustration of gradient structured hydrogel-based solar vapor generation. (c) Optical photo and schematic diagram of gradient structure. SEM images of the (d) $G$ and (e) $T$ sides. Reproduced with permission. ${ }^{167}$ Copyright 2020, Elsevier.

shows stronger water transport capacity over a longer distance than others (Fig. 11h), but it displays a medium SVG performance with an evaporation rate of $2 \mathrm{~kg} \mathrm{~m}^{-2} \mathrm{~h}^{-1}$ at $85.7 \%$ energy conversion efficiency (Fig. 11i). This is relatively lower than that of the hydrogels with vertically aligned channels.

Gradient capillarity has been proved to facilitate strong direction-limited water transport (Fig. 12b) in hydrogels. Liang et $a{ }^{167}$ developed an effective fabrication method based on the G-T template to fabricate gradient structure hydrogels (Fig. 12a), in which $G$ represents glass while $\mathrm{T}$ represents polytetrafluoroethylene (PTFE). From Fig. 12b, it is found that between the top and bottom of the gradient-structured hydrogel, the sizes of the channel is changing continuously. The improved capillary pumping through the channels from the bottom in water to the surface in air results in rapid, one-way water replenishment, allowing for a high evaporation rate (1.684 $\mathrm{kg} \mathrm{m}^{-2} \mathrm{~h}^{-1}$ at $93.4 \%$ energy conversion efficiency) and less heat loss. The optical photos and SEM images of the G side and $\mathrm{T}$ side reveal a considerable difference in the size of the different side channels (Fig. 12c-e).

\subsection{Water activation}

Specific water states in polymer hydrogels can make the water more active, thereby facilitating the evaporation process. Three forms of water have been identified in the hydrated polymer network, including bond water (BW, dark blue color area in Fig. 13a and b) with water-polymer bonding, free water (FW, light blue color area) with water-water bonding, and intermediate water (IW, yellow color area) with weakened water-polymer and water-water bonding between BW and FW. IW is the key water state which requires less energy to escape from the adjacent molecules to decrease the water evaporation enthalpy, realizing higher energy conversion efficiency (according to eqn (1)). Therefore, in order to reduce the energy demand for water evaporation from the hydrogel, it is desirable to tune the building blocks to achieve a higher amount of IW within the hydrogels.

Considerable efforts have been devoted to tuning the IW content in hydrogel networks, including the adjustment of polymer concentration, the introduction of hydrophilic functional groups $\left(-\mathrm{OH},-\mathrm{COOH},-\mathrm{SO}_{3} \mathrm{H},-\mathrm{NH}_{2}\right.$ and $-\mathrm{CONH}-$, to form noncovalent interaction), the change of cross-linking density, and the construction of porous structures. ${ }^{168}$ For example, Zhou et al. ${ }^{137}$ tuned the PVA/CTS ratios from 1:0 to 1:0.25 to form hydrogels, namely h-LAH1-5. Their IW/FW ratios increased, and the equivalent vaporization enthalpy decreased correspondingly, as shown in Fig. 13c and d. However, the evaporation enthalpy is not the only factor that can influence the water evaporation performance. h-LAH5, which has the lowest vaporization enthalpy, still has a high water content, which hinders effective energy utilization and restricts evaporation rate. After balancing these two factors, h-LAH4 with a relatively higher water vaporization enthalpy and relatively lower water content shows the highest evaporation rate of $3.6 \mathrm{~kg} \mathrm{~m}^{-2} \mathrm{~h}^{-1}$ and the best energy conversion efficiency of $92 \%$.

In addition, ionic polymers have electrostatic interaction with water molecules, stronger than hydrogen bonding between polymer chains and water molecules. Zhou et al. ${ }^{84}$ incorporated polystyrene sulfonate (PSS), which can be hydrated with water via electrostatic interaction and hydrogen bonding, into the PVA networks to form a semi-interpenetrating polymer network gel (IPNG, Fig. 13f). IPNG1-5 have different PSS/PVA ratios of $0: 1$, $1: 1,1.5: 1,2: 1$ and $1: 0$, and their IW/FW ratios can be calculated from the differential scanning calorimetry (DSC) curves (Fig. 13e). It is found that with the increase of the PSS content, the ratio of IW/FW increases in response, mainly due to the increase of IW. However, when the IW content reaches the maximum limit, the ratio will drop simply because FW content will continue to increase. As a result, IPNG3 with a PSS/PVA ratio of 1.5 : 1 shows the highest IW/FW ratio and the highest evaporation rate (3.86 $\mathrm{kg} \mathrm{m}^{-2} \mathrm{~h}^{-1}$ ) with an energy conversion efficiency of 92\% (Fig. 13g).
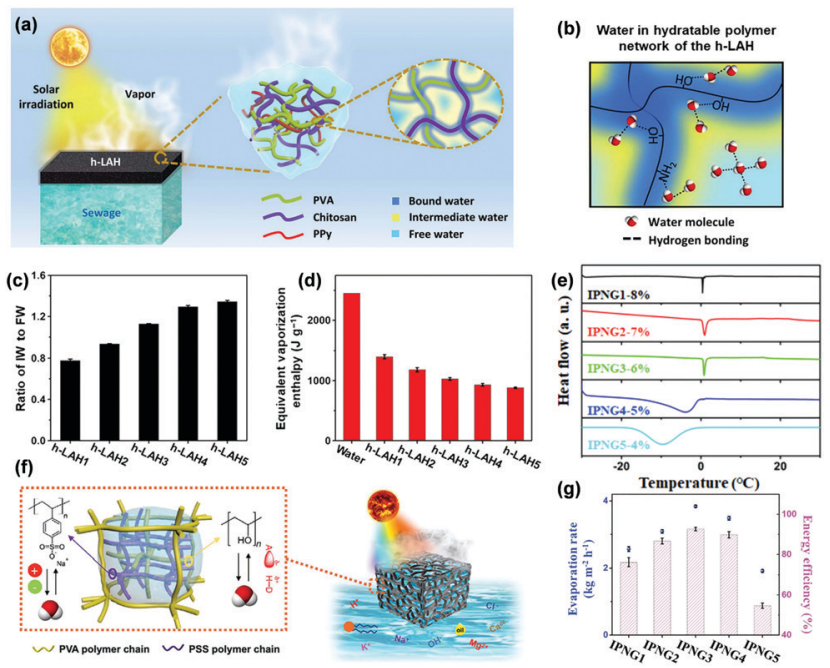

Fig. 13 (a) Schematic illustration of solar vapor generation based on $\mathrm{h}-\mathrm{LAH}$. (b) Water state in h-LAH. (c) The IW/FW ratio in h-LAHs. (d) The equivalent water vaporization enthalpy of bulk water and the water in h-LAHs. Reproduced with permission. ${ }^{137}$ Copyright 2019, American Association for the Advancement of Science. (e) The melting activity of IW in various frozen IPNGs as depicted by DSC curves. (f) Solar water purification with controlled hydration based on IPNG. (g) IPNGs' solar evaporation rate and energy conversion efficiency under 1 sun. Reproduced with permission. ${ }^{84}$ Copyright 2020, John Wiley and Sons. 
In addition to the aforementioned methods, some recent research studies also use polyelectrolyte-based hydrogels as well as some other strategies to implement strong ionic pumping, ${ }^{85}$ construct an overall water management system ${ }^{56,153,169}$ and stimulate water transport and evaporation.

\section{Future research roadmap}

Based on these main design principles, the solar water purification system still has many areas that can be further improved and strengthened to cope with practical water purification issues.

First of all, as shown in Fig. 14 and Table 1, it is still a challenge to achieve a reasonably high evaporation rate and energy conversion efficiency at the same time (for fair comparison, studies with energy conversion efficiency $>100 \%$ are not included). Taking solar water purification with CNTs as solar absorbers as an example, point $\mathrm{B}^{126}$ represents the two-layered biomimetic CNTs/bacterial cellulose hydrogel reported by Guan et al. It shows a high evaporation rate close to $3 \mathrm{~kg} \mathrm{~m}^{-2} \mathrm{~h}^{-1}$, but the energy conversion efficiency is only about $80 \%$. In contrast, Zhou et al. (point $\mathrm{C})^{127}$ proposed a 3D pillared CNTs/PAM hydrogel with selected hydrophobic modification, which has a relatively high energy conversion efficiency (96\%), yet a low evaporation rate $\left(1.42 \mathrm{~kg} \mathrm{~m}^{-2} \mathrm{~h}^{-1}\right)$. In a separate design strategy, most materials only have good performance in limited aspects, but the coordinated design in multiple aspects can bring better and more comprehensive performance. For

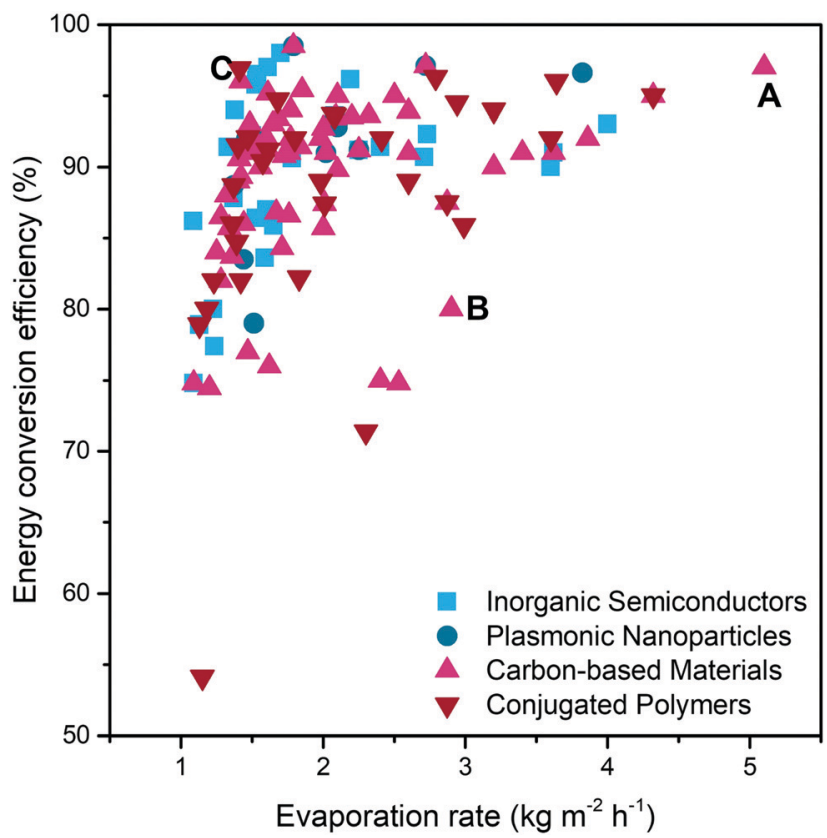

Fig. 14 The diagram summarises the solar water purification performance of different systems. Data acquired from ref. 24-27, 34-36, $42-45,48-69,73-130,132-134,137-153,155-160,162-167$ and 169-184 (all the studies in this figure are under the solar intensity of 1 sun; studies with energy conversion efficiency $>100 \%$ are not included for fair comparison). instance, in a recent study of carboxyl CNTs/PAM composite hydrogels reported by Zhang et al. ${ }^{27}$ (point A), the resulting system exhibited the highest evaporation rate $\left(5.1 \mathrm{~kg} \mathrm{~m}^{-2} \mathrm{~h}^{-1}\right)$ as well as excellent energy conversion efficiency (97\%). This result can be attributed to the use of hydrophobic association in the skeleton and double-layer structure of carbon nanotubes only in the top layer to achieve lower energy loss and ultra-fast water replenishment.

The points representing the hydrogels of carbon-based materials $(\Delta)$ and conjugated polymers $(\nabla)$ appear in almost all ranges of Fig. 14, which means that in most cases, these two solar absorbers are faced with simultaneously achieving high evaporation rate and energy conversion efficiency. In addition, in the existing research shown in Fig. 14, the performance of carbon-based materials is slightly better than that of conjugated polymers, because most of the points representing carbon-based materials are more concentrated in the upper right corner. Most of the hydrogels that use inorganic semiconductors as solar absorbers ( $\square$ ) appear around point C. This reveals that some inorganic semiconductor-based SVGs have problem with high energy conversion efficiency along with low evaporation rate, which needs to be solved in future research. For plasmonic nanoparticles (๑), the energy conversion efficiency and evaporation rate seem to have the same trend. But because there are very few research papers in this field, it is not of valuable reference.

Therefore, on the basis of complying with these design principles, the entire preparation process should be coordinated with each other from the perspectives of chemistry, materials and engineering to maximize the evaporation rate and energy conversion efficiency at the same time.

Since this technique utilizes the most abundant and inexhaustible renewable energy source, which is friendly for developing countries and poverty-stricken areas, lower capital and operating costs will make it more competitive. Using biochar or biomass-derived solar absorbers ${ }^{93-95,173}$ is a regular cost-reducing strategy because the raw materials can be obtained from nature. A research group even coated PPy on the real Setaria viridis spike to use the plant's own water transport and evaporation-promoting properties to maximize its potential. ${ }^{144}$ Other studies have reported the use of specific solid waste as solar absorbers, including red mud (residue of the aluminum mining industry), ${ }^{180}$ semi-coke, ${ }^{183}$ and pencil graphite. ${ }^{178}$ Besides, reducing the use of solar absorbers by distributing them only around the evaporation interface $e^{35,148}$ and constructing multilayerstructure with only one layer of them ${ }^{73,75,83,96,100,141}$ is also effective. Moreover, designing a recyclable solar water purification platform ${ }^{27,105}$ is another proven solution.

In practical application, better anti-fouling performance can guarantee long-term operation, divided into anti-biofouling and crystalline anti-fouling. The anti-bacterial performance can be achieved by adding CTS. ${ }^{43,112}$ Guo et al. ${ }^{184}$ recently attached catechol groups to the CTS hydrogel for hydrogen peroxide (a broad-acting antibacterial agent) generation, combining with the synergistic effect of quinone-modified AC, to enhance the anti-fouling properties and guarantee 3 months of 
Table 1 Different solar water purification systems proposed in recent years and their related performance

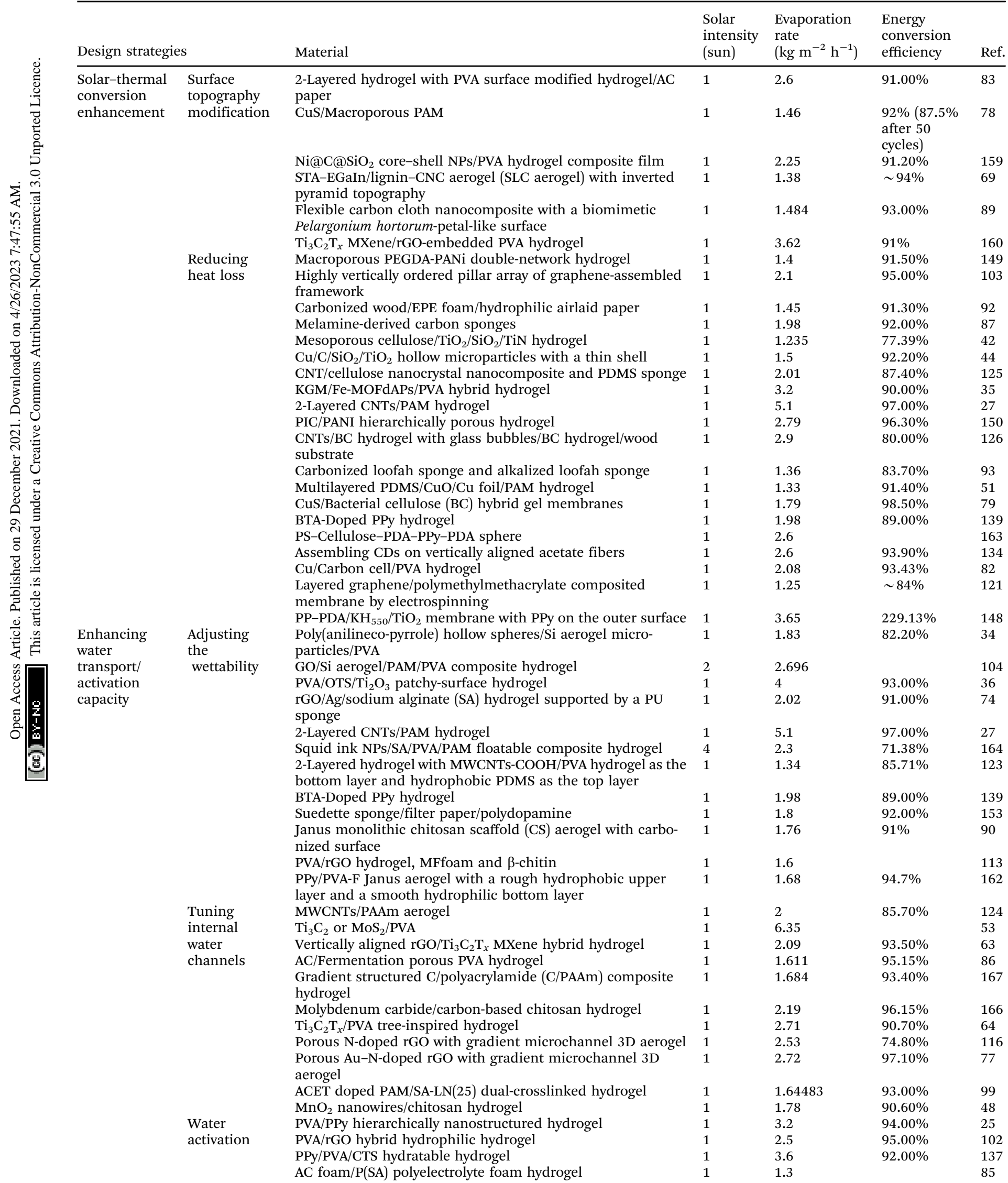


Table 1 (continued)

Material

Solar

intensity

AC/PVA/PSS interpenetrating hydrogel

Sodium alginate/PEDOT/PSS 3D hydrophilic network

Nanofibrous CA/PMAA hydrogel-rGO membrane

3D printed CB NPs/cellulose matrix

Polyurethane (PU) sponge with black hydrogel skin

Others

(sun)

$\mathrm{C}$ dots/CTS/carboxymethyl cellulose hydrogel

Protonated g- $\mathrm{C}_{3} \mathrm{~N}_{4} /$ graphene hybrid hydrogel

Double-layer Ag-PSS-agarose gel/agarose gel

$\mathrm{Mo}_{2} \mathrm{C}+$ PVA hydrogel

PVA or PU or melamine and CB NPs

Evaporation

rate

$\left(\mathrm{kg} \mathrm{m}^{-2} \mathrm{~h}^{-1}\right)$

3.86

1.23

1.85

3.01

2.8

3.6

1.4

1.09

2.1

1.59

2.15 for

PVA based

rGO/PAM hybrid mushroom-like cryogel

$\mathrm{N}$-Doped graphene/carbon hybrid aerogels

PPy coating pre-pressed MF and pre-pressed MF 2 layered hydrogel

Flame-treated melamine foam (F-MF) assembled with

expanding polyethylene (EPE) foam

Large-area polypyrrole chemically functionalized cellulose paper (PPyP)

$\mathrm{Ni}$ foam loading $\mathrm{Co}_{3} \mathrm{O}_{4}$ with nanoscale superstructures

$\mathrm{PPy} / \mathrm{Fe}_{x} \mathrm{O}_{y} / \mathrm{CTS}$ nanostructured gel membrane

2-Layered hydrogel with GO aerogel and chitosan/ZnO composite layer

Copper-zinc-tin-selenide nanocarambola assembled

membrane

Ethanol-treated carrot biochar

$\mathrm{H}_{x} \mathrm{MoO}_{3} /$ PNIPAM hydrogel

Hydrophilic acrylamide polymer (resilience)/biochar parti-

cles/SDS sponge-like hydrogel

2-Layered cellulose-based bottom hydrogel/cellulose-based

CB hydrogel

Graphite nanosheets $/ \mathrm{SiO}_{2} / \mathrm{PVA} / \mathrm{Fe}_{3} \mathrm{O}_{4}$ floating magnetic

hydrogel

2-Layered hydrogel with PPy/Ag/PMBA-BrIL hydrogel as the

top layer and PMBA-BrIL hydrogel as the bottom layer

Squid ink/starch hydrogel

rGO hydrogel membrane

Fe- $\mathrm{Mo}_{2} \mathrm{~S}_{3} /$ sodium alginate starch hydrogel

Modified graphene/coal oxide aerogels

$\mathrm{N}$-Doped maize straw/GO aerogel

G/rGO nanosheets/PVA hydrogel

Plasmonic $\mathrm{Cu}_{7} \mathrm{~S}_{4}-\mathrm{MoS}_{2}$-Au NPs/PDMS

$\mathrm{MOS}_{2} / \mathrm{PU} /$ hydrophilic PDA

Hollow $\mathrm{C}$ nanospheres/porous mixed cellulose ester membrane

Rgo/KGM 3D porous sponge

Mesoporous $\mathrm{CuO}$

CNTs/PAM hydrogel

Self-floating $\mathrm{H}_{1.68} \mathrm{MoO}_{3}$ /airlaid paper photothermal film

A spring wrapped with Rgo/SA@cotton towel

Graphene/PS/PVA

rGO/CA hydrogel

Ppy/polyvalent cation crosslinked alginate hydrogel with styrofoam for floating

PPy/PAAM/chitosan gradient structured hydrogel

Bacterial cellulose-based cellulose nanofibril hydrogels + aerogels

$\mathrm{Bi}_{2} \mathrm{~S}_{3} / \mathrm{Pd}$ PAAH (polyacrylamide/polyacrylic acid hydrogel) GO/PEI/PEG

CB/PVA hydrogel

$\mathrm{BiVO}_{4}-\mathrm{rGO}$ hydrogel

Ag@carbonized melamin foam/MF

Chitosan/gelatin-based IPN sponge incorporated with

melanin-coated titania hollow nanospheres
1.76

1.558

1.574

1.18

2.99

1.226

1.93

1.725

1.528

2.04

1.65

$1.77 \pm 0.05$

1.582

1.196

1.37

2.07

2.33

2.4

1.62

3.22

1.44

3.824

1.087

2

1.6

1.42

1.37

7.6

1.77

1.47

1.15

2.41

$1.82(4.32$

under

light air

conditions

$4 \mathrm{~m} \mathrm{~s}^{-1}$ )

1.61

$97.00 \%$

$88.00 \%$

1.32

2.4

1.6

2.39

1.13

$87.00 \%$
Energy

conversion

$92.00 \% \quad 84$

$82.00 \% \quad 151$

$95.40 \% \quad 120$

$94.00 \% \quad 179$

$90.00 \% \quad 24$

$89.00 \% \quad 133$

$74.8 \% \quad 59$

$92.80 \% \quad 73$

$83.60 \% \quad 61$

$86.60 \% \quad 110$

$90.00 \% \quad 111$

$90.40 \% \quad 141$

$80.00 \% \quad 171$

$85.89 \% \quad 142$

$80.00 \% \quad 50$

$90.80 \% \quad 112$

$86.40 \% \quad 67$

$127.80 \% \quad 94$

$85.87 \% \quad 62$

$94.00 \% \quad 91$

$91.40 \% \quad 100$

$88.70 \% \quad 75$

$93.7 \% \quad 173$

$91.40 \% \quad 57$

$76.00 \% \quad 114$

115

$96.60 \% \quad 26$

$86.20 \% \quad 54$

$92.70 \% \quad 174$

$92.00 \% \quad 118$

$83.66 \% \quad 52$

$96.00 \% \quad 127$

$87.80 \% \quad 175$

$178.60 \% \quad 107$

$92.00 \% \quad 108$

$77.00 \% \quad 109$

$54.12 \% \quad 138$

$92.00 \% \quad 140$

$95.00 \% \quad 97$

$119.46 \% \quad 76$

$78.90 \% \quad 43$ 
Table 1 (continued)

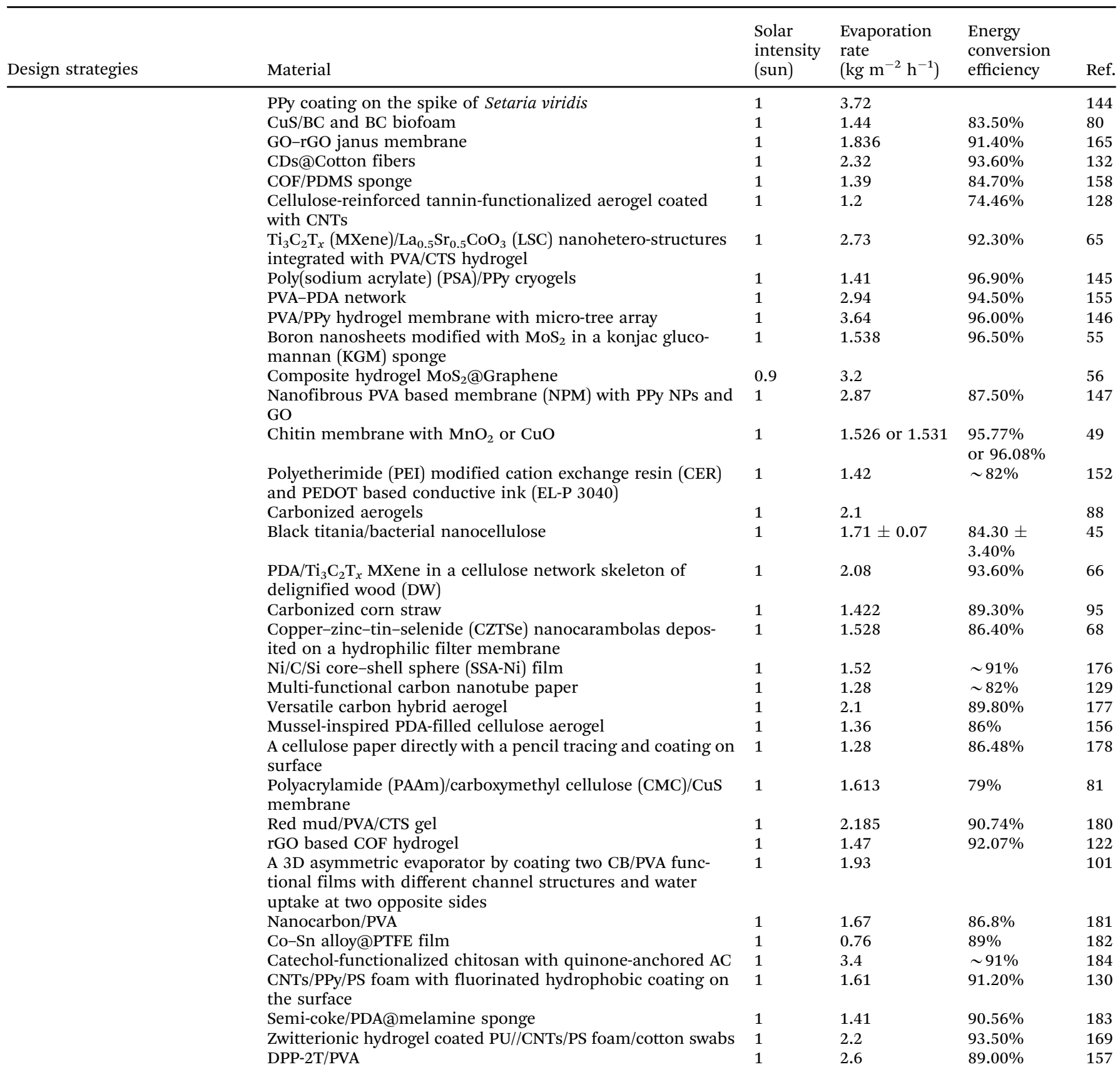

performance maintenance. There are numerous methods to improve the anti-crystalline fouling ability, including the construction of the Janus structure $\mathrm{in}^{130,165}$ and the umbrella-shaped platform, ${ }^{91}$ the use of ions rejection polymer, ${ }^{85,152,169}$ the introduction of bubbles in the middle section, ${ }^{140}$ the weight imbalance sensitive spherical platform capable of rotating and renewing the evaporation surface, ${ }^{163}$ the millineedle array on the surface for site-specific salt crystallization without salt clogging ${ }^{155}$ and so on. In addition, the self-floating hydrogel platform is out of the external support substrate, which is not conducive to water transport, usually by adding low-density materials (i.e. Si aerogels) ${ }^{34}$ or preparing a partially hydrophobic bottom layer. ${ }^{140}$
Drawing inspiration from existing organisms on the planet is another effective strategy to improve solar water purification performance. The most common is to imitate the water absorption of the roots of plants and the water evaporation of the leaves to enhance the water transport process. ${ }^{64,99}$ Inspired from the porifera in the sea, Wang et $a{ }^{179}$ fabricated a hydrogel platform with the sponge as the skeleton and the black hydrogel as the skin, which could be arbitrarily compacted, folded, and twisted as well as remaining stable for more than 6 months in different environments. What's more, imitating the water absorption and release cycle of pufferfish, the inherent lower critical temperature of poly( $N$-isopropyl acrylamide) 
(PNIPAm) hydrogel was used for hydrophilic (in dark conditions) and hydrophobic (under sunlight) conversion. ${ }^{154}$ Additionally, surface biomimetic morphology is also common in studies to enhance light acquisition, ${ }^{69,89}$ anti-fouling, ${ }^{155}$ and additional water collection capacity. ${ }^{146}$

In addition to seawater desalination and wastewater purification, there are still some other particular application scenarios for solar water purification. The recent news that Japan intends to dump nuclear wastewater into the ocean has sparked international concern. Some research groups proposed using solar water purification to purify radioactive wastewater ${ }^{118}$ and recover radioactive elements, e.g. uranium. ${ }^{122,128,158}$ Besides, the application of this technology to purify specific wastewater containing nanoparticles, ${ }^{139}$ acidic, ${ }^{174}$ alkaline, ${ }^{94}$ and lowboiling-point contaminants, ${ }^{177}$ and organic dyes ${ }^{144,156}$ is also under development. Furthermore, additional functions, such as electricity generation, ${ }^{51,88,101,125,127,129,138,185}$ fog collection, ${ }^{146,186,187}$ oil/water separation, ${ }^{147}$ water disinfection, ${ }^{184}$ sensing, ${ }^{58}$ and photo degradability, ${ }^{65,80,188}$ have also been integrated into solar water purification.

\section{Conclusions}

In conclusion, recent progress in solar water purification shows that a higher evaporation rate and energy conversion efficiency can be achieved by designing an entire system from two key aspects of heat and water management. As for the heat management, tailoring surface topography to enhance light harvesting, selecting adequate solar absorbers with stronger full solar spectrum absorption (especially the infrared band) and higher photothermal conversion ability, and minimizing heat loss to the atmosphere and bulk water by managing the distribution of solar absorbers and heat insulation components proved to be effective strategies for harvesting sunlight. Concerning water management, adjusting wettability to ensure rapid water replenishment, tuning the size, direction and structure of the internal channel to enhance the channel pumping, and increasing the IW content in hydrogels to lower water vaporization enthalpy are the three main approaches that have been successfully implemented. However, it is still a challenge to maximize the evaporation rate and energy conversion efficiency concurrently, requiring coordination from chemistry, materials, engineering and other aspects. Additionally, lower capital and operating costs, better anti-fouling performance, self-floating capability, biomimetic design and additional integrated functions are the possible future development directions.

\section{Conflicts of interest}

There are no conflicts to declare.

\section{Acknowledgements}

Qiang Fu acknowledges the Australian Research Council under the Future Fellowship (FT180100312). Shudi Mao acknowledges support from the China Scholarship Council (CSC) Scholarship (202006140015).

\section{Notes and references}

1 D. N. Chakkaravarthy, Int. J. Agric. Environ. Biotechnol., 2019, 12, 187-193.

2 W. W. Immerzeel, L. P. Van Beek and M. F. Bierkens, Science, 2010, 328, 1382-1385.

3 Y. Wada, M. Flörke, N. Hanasaki, S. Eisner, G. Fischer, S. Tramberend, Y. Satoh, M. Van Vliet, P. Yillia and C. Ringler, Geosci. Model Dev., 2016, 9, 175-222.

4 C. A. Schlosser, K. Strzepek, X. Gao, C. Fant, É. Blanc, S. Paltsev, H. Jacoby, J. Reilly and A. Gueneau, Earth's Future, 2014, 2, 341-361.

5 P. Goh, A. Ismail and N. Hilal, Oxford Research Encyclopedia of Environmental Science, 2019.

6 A. Panagopoulos, K.-J. Haralambous and M. Loizidou, Sci. Total Environ., 2019, 693, 133545.

7 R. Semiat, Environ. Sci. Technol., 2008, 42, 8193-8201.

8 A. D. Khawaji, I. K. Kutubkhanah and J.-M. Wie, Desalination, 2008, 221, 47-69.

9 F. A. AlMarzooqi, A. A. Al Ghaferi, I. Saadat and N. Hilal, Desalination, 2014, 342, 3-15.

10 R. M. Morris, Desalination, 1993, 93, 57-68.

11 H. Bamufleh, F. Abdelhady, H. M. Baaqeel and M. M. ElHalwagi, Desalination, 2017, 408, 110-118.

12 A. Al-Karaghouli and L. L. Kazmerski, Renewable Sustainable Energy Rev., 2013, 24, 343-356.

13 M. Qasim, M. Badrelzaman, N. N. Darwish, N. A. Darwish and N. Hilal, Desalination, 2019, 459, 59-104.

14 H. Strathmann, Desalination, 2010, 264, 268-288.

15 J. R. Werber, A. Deshmukh and M. Elimelech, Environ. Sci. Technol. Lett., 2016, 3, 112-120.

16 R. Zhao, S. Porada, P. Biesheuvel and A. Van der Wal, Desalination, 2013, 330, 35-41.

17 N. Ghaffour, T. M. Missimer and G. L. Amy, Desalination, 2013, 309, 197-207.

18 C. Y. Tang, Z. Yang, H. Guo, J. J. Wen, L. D. Nghiem and E. Cornelissen, Environ. Sci. Technol., 2018, 52, 10215-10223.

19 N. A. A. Qasem, S. M. Zubair, B. A. Qureshi and M. M. Generous, Energy Convers. Manage., 2020, 205, 112448.

20 S. Al-Amshawee, M. Y. B. M. Yunus, A. A. M. Azoddein, D. G. Hassell, I. H. Dakhil and H. A. Hasan, Chem. - Eng. J., 2020, 380, 122231.

21 H. C. Duong, L. Xia, Z. Ma, P. Cooper, W. Ela and L. D. Nghiem, J. Membr. Sci., 2017, 542, 133-142.

22 S. Sharshir, G. Peng, L. Wu, F. Essa, A. Kabeel and N. Yang, Appl. Energy, 2017, 191, 358-366.

23 Y. Zhang, M. Sivakumar, S. Yang, K. Enever and M. Ramezanianpour, Desalination, 2018, 428, 116-145.

24 Y. Guo, X. Zhou, F. Zhao, J. Bae, B. Rosenberger and G. Yu, ACS Nano, 2019, 13, 7913-7919. 
25 F. Zhao, X. Zhou, Y. Shi, X. Qian, M. Alexander, X. Zhao, S. Mendez, R. Yang, L. Qu and G. Yu, Nat. Nanotechnol., 2018, 13, 489-495.

26 H. Wang, R. Zhang, D. Yuan, S. Xu and L. Wang, Adv. Funct. Mater., 2020, 30, 2003995.

27 X. Zhang, Y. Peng, L. Shi and R. Ran, ACS Sustainable Chem. Eng., 2020, 8, 18114-18125.

28 D. Lapotko, Opt. Express, 2009, 17, 2538-2556.

29 Y. Guo, J. Bae, Z. Fang, P. Li, F. Zhao and G. Yu, Chem. Rev., 2020, 120, 7642-7707.

30 X. Zhou, Y. Guo, F. Zhao and G. Yu, Acc. Chem. Res., 2019, 52, 3244-3253.

31 Z. Xu, Z. Li, Y. Jiang, G. Xu, M. Zhu, W.-C. Law, K.-T. Yong, Y. Wang, C. Yang, B. Dong and F. Xing, J. Mater. Chem. A, 2020, 8, 25571.

32 M. Gao, L. Zhu, C. K. Peh and G. W. Ho, Energy Environ. Sci., 2019, 12, 841-864.

33 L. Zhu, M. Gao, C. K. N. Peh and G. W. Ho, Nano Energy, 2019, 57, 507-518.

34 M. Tan, J. Wang, W. Song, J. Fang and X. Zhang, J. Mater. Chem. A, 2019, 7, 1244-1251.

35 Y. Guo, H. Lu, F. Zhao, X. Zhou, W. Shi and G. Yu, Adv. Mater., 2020, 32, 1907061.

36 Y. Guo, X. Zhao, F. Zhao, Z. Jiao, X. Zhou and G. Yu, Energy Environ. Sci., 2020, 13, 2087-2095.

37 F. Yu, Y. Chen, X. Liang, J. Xu, C. Lee, Q. Liang, P. Tao and T. Deng, Prog. Nat. Sci.: Mater. Int., 2017, 27, 531-542.

38 Y. Zhao and C. Burda, Energy Environ. Sci., 2012, 5, 5564-5576.

39 F. Zhao, Y. Guo, X. Zhou, W. Shi and G. Yu, Nat. Rev. Mater., 2020, 5, 388-401.

40 C. M. Hessel, V. P. Pattani, M. Rasch, M. G. Panthani, B. Koo, J. W. Tunnell and B. A. Korgel, Nano Lett., 2011, 11, 2560-2566.

41 A. Standard, Ann. Book ASTM Standards, 2012, 14, 1-20.

42 Z. Sun, Z. Li, W. Li and F. Bian, Cellulose, 2019, 27, 481-491.

43 X. Wang, Z. Li, Y. Wu, H. Guo, X. Zhang, Y. Yang, H. Mu and J. Duan, ACS Appl. Mater. Interfaces, 2021, 13, 10902-10915.

44 X. Zhang, X. Wang, W. D. Wu, X. D. Chen and Z. Wu, J. Mater. Chem. A, 2019, 7, 6963-6971.

45 K. Nabeela, M. N. Thorat, S. N. Backer, A. M. Ramachandran, R. T. Thomas, G. Preethikumar, A. P. Mohamed, A. Asok, S. G. Dastager and S. Pillai, ACS Appl. Bio Mater., 2021, 4, 4373-4383.

46 C. Dette, M. A. Pérez-Osorio, C. S. Kley, P. Punke, C. E. Patrick, P. Jacobson, F. Giustino, S. J. Jung and K. Kern, Nano Lett., 2014, 14, 6533-6538.

47 J. Tao, T. Luttrell and M. Batzill, Nat. Chem., 2011, 3, 296-300.

48 M. S. Irshad, X. Wang, M. S. Abbasi, N. Arshad, Z. Chen, Z. Guo, L. Yu, J. Qian, J. You and T. Mei, ACS Sustainable Chem. Eng., 2021, 9, 3887-3900.

49 X. Li, J. Huang, L. Guo, X. Jin, L. Wang, Y. Deng, H. Xie and L. Ye, Inorg. Chem. Commun., 2021, 129, 108651.
50 P. Wang, Y. Gu, L. Miao, J. Zhou, H. Su, A. Wei, X. Mu, Y. Tian, J. Shi and H. Cai, Sustainable Mater. Technol., 2019, 20, e00106.

51 F. L. Meng, M. Gao, T. Ding, G. Yilmaz, W. L. Ong and G. W. Ho, Adv. Funct. Mater., 2020, 30, 2002867.

52 H. Zhang, K. Wang, L. Wang, H. Xie and W. Yu, Sol. Energy, 2020, 201, 628-637.

53 C. Li, L. Fan, R. Zhu, X. Li, P. Wen, X. Zhao, G. Wang, J. Zou and F. Kim, ACS Appl. Energy Mater., 2020, 3, 9216-9225.

54 Q. Wang, F. Jia, A. Huang, Y. Qin, S. Song, Y. Li and M. A. C. Arroyo, Desalination, 2020, 481, 114359.

55 J. Yin, X. You, Z. Zhang, Z. Guo, J. Wang and X. Wang, J. Water Process Eng., 2021, 41, 102048.

56 Y. Li, X.-l. Shi, L.-j. Sun, M. Zhao, T. Jiang, W. Jiang, M. Deng, S. Yang and Y. Wang, Desalination, 2021, 515, 115192.

57 Z. Guo, F. Yu, Z. Chen, Z. Shi, J. Wang and X. Wang, Sol. Energy Mater. Sol. Cells, 2020, 211, 110531.

58 X. Geng, D. Zhang, Z. Zheng, G. Ye, S. Li, H. Tu, Y. Wan and P. Yang, Nano Energy, 2021, 82, 105700.

59 H. Su, J. Zhou, L. Miao, J. Shi, Y. Gu, P. Wang, Y. Tian, X. Mu, A. Wei, L. Huang, S. Chen and Z. Deng, Sustainable Mater. Technol., 2019, 20, e00095.

60 L. Zhu, L. Sun, H. Zhang, D. Yu, H. Aslan, J. Zhao, Z. Li, M. Yu, F. Besenbacher and Y. Sun, Nano Energy, 2019, 57, 842-850.

61 F. Yu, X. Ming, Y. Xu, Z. Chen, D. Meng, H. Cheng, Z. Shi, P. Shen and X. Wang, Adv. Mater. Interfaces, 2019, 6, 1901168.

62 S. Cao, J. Jiang, Q. Tian, C. Guo, X. Wang, K. Dai and Q. Xu, Green Energy Environ., 2020, DOI: 10.1016/j.gee.2020.12.012.

63 W. Li, X. Li, W. Chang, J. Wu, P. Liu, J. Wang, X. Yao and Z.-Z. Yu, Nano Res., 2020, 13, 3048-3056.

64 Z. Yu and P. Wu, Adv. Mater. Technol., 2020, 5, 2000065.

65 D. Fan, Y. Lu, H. Zhang, H. Xu, C. Lu, Y. Tang and X. Yang, Appl. Catal., B, 2021, 295, 120285.

66 Y. Chen, J. Yang, L. Zhu, X. Jia, S. Wang, Y. Li and H. Song, J. Mater. Chem. A, 2021, 9, 15482-15492.

67 Y. Yang, W. Que, J. Zhao, Y. Han, M. Ju and X. Yin, Chem. Eng. J., 2019, 373, 955-962.

68 L. Yang, N. Li, C. Guo, J. He, S. Wang, L. Qiao, F. Li, L. Yu, M. Wang and X. Xu, Chem. - Eng. J., 2021, 417, 128051.

69 Z. Wei, C. Cai, Y. Huang, Y. Wang and Y. Fu, Nano Energy, 2021, 86, 106138.

70 Z. W. Seh, S. Liu, M. Low, S. Y. Zhang, Z. Liu, A. Mlayah and M. Y. Han, Adv. Mater., 2012, 24, 2310-2314.

71 M. Gao, P. K. N. Connor and G. W. Ho, Energy Environ. Sci., 2016, 9, 3151-3160.

72 L. Zhu, M. Gao, C. K. N. Peh and G. W. Ho, Mater. Horiz., 2018, 5, 323-343.

73 Z. Sun, J. Wang, Q. Wu, Z. Wang, Z. Wang, J. Sun and C. J. Liu, Adv. Funct. Mater., 2019, 29, 1901312.

74 C. Liu, C. Cai, F. Ma, X. Zhao and H. Ahmad, J. Colloid Interface Sci., 2020, 560, 103-110.

75 C. Xiao, W. Liang, Q.-M. Hasi, L. Chen, J. He, F. Liu, C. Wang, H. Sun, Z. Zhu and A. Li, Mater. Today Energy, 2020, 16, 100417. 
76 Y. Shi, C. Zhang, Y. Wang, Y. Cui, Q. Wang, G. Liu, S. Gao and Y. Yuan, Desalination, 2021, 507, 115038.

77 X. Meng, J. Yang, S. Ramakrishna, Y. Sun and Y. Dai, J. Mater. Chem. A, 2020, 8, 16570-16581.

78 Y. Sun, J. Gao, Y. Liu, H. Kang, M. Xie, F. Wu and H. Qiu, Chem. Eng. Sci., 2019, 207, 516-526.

79 D. Zhang, Y. Cai, Q. Liang, Z. Wu, N. Sheng, M. Zhang, B. Wang and S. Chen, ACS Sustainable Chem. Eng., 2020, 8, 9017-9026.

80 D. Zhang, M. H. Zhang, S. Y. Chen, Q. Q. Liang, N. Sheng, Z. L. Han, Y. X. Cai and H. P. Wang, Desalination, 2021, $500,10$.

81 J. Chen, D. Wang, X. Li, H. Sun, H. Zhao, Y. Li, X. Liu and G. Shi, ACS Appl. Polym. Mater., 2021, 3, 2402-2410.

82 C. Tian, C. Li, D. Chen, Y. Li, L. Xing, X. Tian, Y. Cao, W. Huang, Z. Liu and Y. Shen, J. Mater. Chem. A, 2021, 9, 15462-15471.

83 Y. Guo, F. Zhao, X. Zhou, Z. Chen and G. Yu, Nano Lett., 2019, 19, 2530-2536.

84 X. Zhou, Y. Guo, F. Zhao, W. Shi and G. Yu, Adv. Mater., 2020, 32, 2007012.

85 J. Zeng, Q. Wang, Y. Shi, P. Liu and R. Chen, Adv. Energy Mater., 2019, 9, 1900552.

86 X. Liang, X. Zhang, Q. Huang, H. Zhang, C. Liu and Y. Liu, Sol. Energy, 2020, 208, 778-786.

87 F. Gong, H. Li, W. Wang, J. Huang, D. Xia, J. Liao, M. Wu and D. V. Papavassiliou, Nano Energy, 2019, 58, 322-330.

88 J. Liu, X. Chen, H. Yang, J. Tang, R. Miao, K. Liu and Y. Fang, Mater. Chem. Front., 2021, 5, 1953-1961.

89 Y. Xu, Z. Guo, J. Wang, Z. Chen, J. Yin, Z. Zhang, J. Huang, J. Qian and X. Wang, ACS Appl. Mater. Interfaces, 2021, 13, 27129-27139.

90 Z. Liu, R.-K. Qing, A.-Q. Xie, H. Liu, L. Zhu and S. Chen, ACS Appl. Mater. Interfaces, 2021, 13, 18829-18837.

91 X. Chen, Z. Wu, D. Lai, M. Zheng, L. Xu, J. Huo, Z. Chen, B. Yuan and M.-L. Fu, J. Mater. Chem. A, 2020, 8, 22645-22656.

92 P.-F. Liu, L. Miao, Z. Deng, J. Zhou, H. Su, L. Sun, S. Tanemura, W. Cao, F. Jiang and L.-D. Zhao, Mater. Today Energy, 2018, 8, 166-173.

93 Y. Lu, X. Wang, D. Fan, H. Yang, H. Xu, H. Min and X. Yang, Sustainable Mater. Technol., 2020, 25, e00180.

94 Y. Long, S. Huang, H. Yi, J. Chen, J. Wu, Q. Liao, H. Liang, H. Cui, S. Ruan and Y.-J. Zeng, J. Mater. Chem. A, 2019, 7, 26911-26916.

95 J. Feng, B. Bai, L. Yang, N. Hu and H. Wang, Mater. Chem. Phys., 2021, 271, 124904.

96 H. Lu, W. Shi, F. Zhao, W. Zhang, P. Zhang, C. Zhao and G. Yu, Adv. Funct. Mater., 2021, 31, 2101036.

97 N. Li, L. Qiao, J. He, S. Wang, L. Yu, P. Murto, X. Li and X. Xu, Adv. Funct. Mater., 2021, 31, 2008681.

98 Z. Deng, L. Miao, P.-F. Liu, J. Zhou, P. Wang, Y. Gu, X. Wang, H. Cai, L. Sun and S. Tanemura, Nano Energy, 2019, 55, 368-376.

99 J. X. He, Y. K. Fan, C. H. Xiao, F. Liu, H. X. Sun, Z. Q. Zhu, W. D. Liang and A. Li, Compos. Sci. Technol., 2021, 204, 9.
100 N. Hu, Y. Xu, Z. Liu, M. Liu, X. Shao and J. Wang, Carbohydr. Polym., 2020, 243, 116480.

101 J. Liu, J. Gui, W. Zhou, X. Tian, Z. Liu, J. Wang, L. Yang, P. Zhang, W. Huang and J. Tu, Nano Energy, 2021, 86, 106112.

102 X. Zhou, F. Zhao, Y. Guo, Y. Zhang and G. Yu, Energy Environ. Sci., 2018, 11, 1985-1992.

103 P. Zhang, Q. Liao, H. Yao, H. Cheng, Y. Huang, C. Yang, L. Jiang and L. Qu, J. Mater. Chem. A, 2018, 6, 15303-15309.

104 L. Zhao, P. Wang, J. Tian, J. Wang, L. Li, L. Xu, Y. Wang, X. Fei and Y. Li, Sci. Total Environ., 2019, 668, 153-160.

105 Y. Liu, J. Tian, L. Xu, Y. Wang, X. Fei and Y. Li, New J. Chem., 2020, 44, 20181-20191.

106 P. Zhuang, D. Li, N. Xu, X. Yu and L. Zhou, Global Challenges, 2020, 5, 2000053.

107 T. Gao, X. Wu, Y. Wang, G. Owens and H. Xu, Sol. RRL, 2021, 5, 2100053.

108 W. Lei, S. Khan, L. Chen, N. Suzuki, C. Terashima, K. Liu, A. Fujishima and M. Liu, Nano Res., 2021, 14, 1135-1140.

109 G. Lou, Y. Wang, Y. Ma, J. Kou, F. Wu and J. Fan, Front. Mater. Sci., 2021, 15, 138-146.

110 C.-S. Hu, H.-J. Li, J.-Y. Wang, A. Haleem, X.-C. Li, M. Siddiq and W.-D. He, ACS Appl. Energy Mater., 2019, 2, 7554-7563.

111 B. Huo, D. Jiang, X. Cao, H. Liang, Z. Liu, C. Li and J. Liu, Carbon, 2019, 142, 13-19.

112 X.-Y. Wang, J. Xue, C. Ma, T. He, H. Qian, B. Wang, J. Liu and Y. Lu, J. Mater. Chem. A, 2019, 7, 16696-16703.

113 H. Geng, C. Lv, M. Wu, H. Ma, H. Cheng, C. Li, J. Yuan and L. Qu, Global Challenges, 2020, 4, 2000043.

114 S. Hou, Y. Lv, X. Wu, J. Guo, Q. Sun, L. Wang and D. Jia, New J. Chem., 2020, 44, 2228-2235.

115 Y. Kong, H. Dan, W. Kong, Y. Gao, Y. Shang, K. Ji, Q. Yue and B. Gao, J. Mater. Chem. A, 2020, 8, 24734-24742.

116 X. Meng, J. Yang, S. Ramakrishna, Y. Sun and Y. Dai, ACS Sustainable Chem. Eng., 2020, 8, 4955-4965.

117 J. Tian, X. Huang and W. Wu, Ind. Eng. Chem. Res., 2020, 59, 1135-1141.

118 K. Yu, P. Shao, P. Meng, T. Chen, J. Lei, X. Yu, R. He, F. Yang, W. Zhu and T. Duan, J. Hazard. Mater., 2020, 392, 122350.

119 C. Liu, Y. Peng and X. Zhao, Desalination, 2021, 501, 114911.

120 L. Zang, L. Sun, S. Zhang, C. Finnerty, A. Kim, J. Ma and B. Mi, Chem. Eng. J., 2021, 422, 129998.

121 D. Li, X. Zhang, S. Zhang, D. Wang, Z. Wang, Y. Liu, X. Yu, Q. Zhao and B. Xing, Chemosphere, 2021, 267, 128916.

122 C.-R. Zhang, W.-R. Cui, C.-P. Niu, S.-M. Yi, R.-P. Liang, J.-X. Qi, X.-J. Chen, W. Jiang, L. Zhang and J.-D. Qiu, Chem. Eng. J., 2021, 428, 131178.

123 H. Jian, Q. Qi, W. Wang and D. Yu, Sep. Purif. Technol., 2021, 264, 118459.

124 W. Xu, Y. Xing, J. Liu, H. Wu, Y. Cui, D. Li, D. Guo, C. Li, A. Liu and H. Bai, ACS Nano, 2019, 13, 7930-7938.

125 L. Zhu, T. Ding, M. Gao, C. K. N. Peh and G. W. Ho, Adv. Energy Mater., 2019, 9, 1900250. 
126 Q. F. Guan, Z. M. Han, Z. C. Ling, H. B. Yang and S. H. Yu, Nano Lett., 2020, 20, 5699-5704.

127 Y. Zhou, T. Ding, M. Gao, K. H. Chan, Y. Cheng, J. He and G. W. Ho, Nano Energy, 2020, 77, 105102.

128 X. Luo, J. Zhang, J. Tao, X. Wang, S. Zhao, Z. Chen, S. Liu, J. Li and S. Li, Chem. - Eng. J., 2021, 416, 129486.

129 Y. Duan, M. Weng, W. Zhang, Y. Qian, Z. Luo and L. Chen, Energy Convers. Manage., 2021, 241, 114306.

130 S. Sun, Y. Wang, B. Sun, F. Zhang, Q. Xu, H.-Y. Mi, H. Li, X. Tao, Z. Guo and C. Liu, ACS Appl. Mater. Interfaces, 2021, 13, 24945-24956.

131 Q. Zhao, T. Fan, J. Ding, D. Zhang, Q. Guo and M. Kamada, Carbon, 2011, 49, 877-883.

132 W. Zhang, Q. Chang, C. Xue, J. Yang and S. Hu, Sol. RRL, 2021, 5, 2100133.

133 S. Singh, N. Shauloff and R. Jelinek, ACS Sustainable Chem. Eng., 2019, 7, 13186-13194.

134 H. Zhou, C. Xue, Q. Chang, J. Yang and S. Hu, Chem. - Eng. J., 2021, 421, 129822.

135 Indriyati, I. Primadona, F. A. A. Permatasari, M. A. Irham, D. E. M. Nasir and F. Iskandar, Nanoscale, 2021, 13, 7523-7532.

136 L. Xu, L. Cheng, C. Wang, R. Peng and Z. Liu, Polym. Chem., 2014, 5, 1573-1580.

137 X. Zhou, F. Zhao, Y. Guo, B. Rosenberger and G. Yu, Sci. $A d v .$, 2019, 5, eaaw5484.

138 S. H. Park, J. H. Park, J. Kim and S. J. Lee, Desalination, 2021, 500, 114900.

139 Y. Wu, L. Shen, C. Zhang, H. Gao, J. Chen, L. Jin, P. Lin, H. Zhang and Y. Xia, Desalination, 2021, 505, 114766.

140 T. Xu, Y. Xu, J. Wang, H. Lu, W. Liu and J. Wang, Chem. Eng. J., 2021, 415, 128893.

141 C. Li, D. Jiang, B. Huo, M. Ding, C. Huang, D. Jia, H. Li, C.-Y. Liu and J. Liu, Nano Energy, 2019, 60, 841-849.

142 F. Ni, P. Xiao, C. Zhang, Y. Liang, J. Gu, L. Zhang and T. Chen, ACS Appl. Mater. Interfaces, 2019, 11, 15498-15506.

143 W. Wang, J. Niu, J. Guo, L. Yin and H. Huang, Sol. Energy Mater. Sol. Cells, 2019, 201, 110046.

144 Z. Xie, J. Zhu and L. Zhang, ACS Appl. Mater. Interfaces, 2021, 13, 9027-9035.

145 S.-L. Loo, L. Vásquez, M. Zahid, F. Costantino, A. Athanassiou and D. Fragouli, ACS Appl. Mater. Interfaces, 2021, 13, 30542-30555.

146 Y. Shi, O. Ilic, H. A. Atwater and J. R. Greer, Nat. Commun., 2021, 12, 1-10.

147 S. Chen, Y. Liu, Y. Wang, K. Xu, X. Zhang, W. Zhong, G. Luo and M. Xing, Chem. - Eng. J., 2021, 411, 128042.

148 C. Wei, X. Zhang, S. Ma, C. Zhang, Y. Li, D. Chen, H. Jiang, Z. Xu and X. Huang, Chem. - Eng. J., 2021, 425, 130118.

149 X. Yin, Y. Zhang, Q. Guo, X. Cai, J. Xiao, Z. Ding and J. Yang, ACS Appl. Mater. Interfaces, 2018, 10, 10998-11007.

150 F. Zhu, L. Wang, B. Demir, M. An, Z. L. Wu, J. Yin, R. Xiao, Q. Zheng and J. Qian, Mater. Horiz., 2020, 7, 3187-3195.

151 X. Zhao and C. Liu, Desalination, 2020, 482, 114385.
152 C. Liu, Y. Peng, C. Cai, J. Zhang and X. Zhao, J. Environ. Chem. Eng., 2021, 9, 105272.

153 Y. Sun, X. Zong, D. Qu, G. Chen, L. An, X. Wang and Z. Sun, J. Mater. Chem. A, 2021, 9, 7122-7128.

154 X. Xu, S. Ozden, N. Bizmark, C. B. Arnold, S. S. Datta and R. D. Priestley, Adv. Mater., 2021, 33, 2007833.

155 Z. Huang, J. Wei, Y. Wan, P. Li, J. Yu, J. Dong, S. Wang, S. Li and C. S. Lee, Small, 2021, 2101487, DOI: 10.1002/ smll.202101487.

156 Y. Zou, J. Zhao, J. Zhu, X. Guo, P. Chen, G. Duan, X. Liu and Y. Li, ACS Appl. Mater. Interfaces, 2021, 13, 7617-7624.

157 Q. Zhao, Z. Huang, Y. Wan, J. Tan, C. Cao, S. Li and C.-S. Lee, J. Mater. Chem. A, 2021, 9, 2104-2110.

158 W. R. Cui, C. R. Zhang, R. P. Liang, J. Liu and J. D. Qiu, ACS Appl. Mater. Interfaces, 2021, 13, 31561-31568.

159 F. Yang, J. X. Chen, Z. Y. Ye, D. W. Ding, N. V. Myung and Y. D. Yin, Adv. Funct. Mater., 2021, 31, 9.

160 Y. Lu, D. Fan, Y. Wang, H. Xu, C. Lu and X. Yang, ACS Nano, 2021, 15, 10366-10376.

161 J. Yuan, X. Lei, C. Yi, H. Jiang, F. Liu and G. J. Cheng, Chem. - Eng. J., 2021, 132765, DOI: 10.1016/j.cej. 2021.132765.

162 B. Wen, X. Zhang, Y. Yan, Y. Huang, S. Lin, Y. Zhu, Z. Wang, B. Zhou, S. Yang and J. Liu, Desalination, 2021, 516, 115228.

163 X. Wu, Y. Wang, P. Wu, J. Zhao, Y. Lu, X. Yang and H. Xu, Adv. Funct. Mater., 2021, 31, 2102618.

164 L. Zhao, J. Tian, Y. Liu, L. Xu, Y. Wang, X. Fei and Y. Li, Environ. Sci.: Water Res. Technol., 2020, 6, 221-230.

165 H. Zhang, H. Xie, W. Han, X. Yan, X. Liu, L. He, P. Lin, Y. Xia, K. Zhang, J. A. Zapien and K.-B. Yoon, ACS Appl. Nano Mater., 2021, 4, 1916-1923.

166 F. Yu, Z. Chen, Z. Guo, M. S. Irshad, L. Yu, J. Qian, T. Mei and X. Wang, ACS Sustainable Chem. Eng., 2020, 8, 7139-7149.

167 X. Liang, X. Zhang, Z. Liu, Q. Huang, H. Zhang, C. Liu and Y. Liu, Sol. Energy, 2020, 201, 581-588.

168 Y. Guo and G. Yu, Acco. Mater. Res., 2021, 2, 374-384.

169 C. Wen, H. Guo, J. Yang, Q. Li, X. Zhang, X. Sui, M. Cao and L. Zhang, Chem. - Eng. J., 2021, 421, 130344.

170 J. J. Koh, G. J. H. Lim, S. Chakraborty, Y. Zhang, S. Liu, X. Zhang, S. C. Tan, Z. Lyu, J. Ding and C. He, Nano Energy, 2021, 79, 105436.

171 P.-F. Liu, L. Miao, Z. Deng, J. Zhou, Y. Gu, S. Chen, H. Cai, L. Sun and S. Tanemura, Appl. Energy, 2019, 241, 652-659.

172 L. L. Noureen, Z. J. Xie, M. Hussain, M. M. Li, Q. Q. Lyu, K. Wang, L. B. Zhang and J. T. Zhu, Sol. Energy Mater. Sol. Cells, 2021, 222, 7.

173 Y. Xu, X. Xiao, X. Fan, Y. Yang, C. Song, Y. Fan and Y. Liu, J. Mater. Chem. A, 2020, 8, 24108-24116.

174 H. Yang, G. Yang, Z. Qiao, H. Bao, S. Zhang, X. Li and Y. Liu, ACS Appl. Mater. Interfaces, 2020, 12, 35193-35200.

175 Q. Zhu, K. Ye, W. Zhu, W. Xu, C. Zou, L. Song, E. Sharman, L. Wang, S. Jin, G. Zhang, Y. Luo and J. Jiang, J. Phys. Chem. Lett., 2020, 11, 2502-2509. 
176 D. Ding, H. Wu, X. He, F. Yang, C. Gao, Y. Yin and S. Ding, J. Mater. Chem. A, 2021, 9, 11241-11247.

177 Z. Huang, Y. Wan, J. Liang, Y. Xiao, X. Li, X. Cui, S. Tian, Q. Zhao, S. Li and C.-S. Lee, ACS Appl. Mater. Interfaces, 2021, 13, 31624-31634.

178 M. Z. Tariq, Z. Hanif, M. La, D. Choi and S. J. Park, Int. J. Energy Res., 2021, 45, 6395-6404.

179 Z. Wang, X. Wu, J. Dong, X. Yang, F. He, S. Peng and Y. Li, Chem. - Eng. J., 2022, 427, 130905.

180 P. Wang, X. Wang, S. Chen, J. Zhang, X. Mu, Y. Chen, Z. Sun, A. Wei, Y. Tian and J. Zhou, ACS Appl. Mater. Interfaces, 2021, 13, 30556-30564.

181 Y. Li, W. Hong, H. Li, Z. Yan, S. Wang, X. Liu, B. Li, H. Jiang and X. Niu, Desalination, 2021, 511, 115113.
182 Y. Wang, L. Zhao, F. Zhang, K. Yu, C. Yang, J. Jia, W. Guo, J. Zhao and F. Qu, ACS Appl. Mater. Interfaces, 2021, 13, 26879-26890.

183 L. Zhang, X. Xu, J. Feng, B. Bai, N. Hu and H. Wang, Sol. Energy Mater. Sol. Cells, 2021, 230, 111237.

184 Y. Guo, C. M. Dundas, X. Zhou, K. P. Johnston and G. Yu, Adv. Mater., 2021, 2102994, DOI: 10.1002/adma.202102994.

185 X. Zhou, F. Zhao, P. Zhang and G. Yu, ACS Mater. Lett., 2021, 1112-1129, DOI: 10.1021/acsmaterialslett.1c00304.

186 F. Zhao, X. Zhou, Y. Liu, Y. Shi, Y. Dai and G. Yu, Adv. Mater., 2019, 31, e1806446.

187 X. Zhou, H. Lu, F. Zhao and G. Yu, ACS Mater. Lett., 2020, 2, 671-684.

188 Y. Guo, Z. Fang and G. Yu, Polym. Int., 2021, 70, 1425-1432. 